\title{
RECENTES AVANÇOS EM REAÇÕES ORGÂNICAS CATALISADAS POR NÍQUEL
}

\section{Danielle L. J. Pinheiro a Giovanni W. Amarante ${ }^{a, *}$}

aDepartamento de Química, Universidade Federal de Juiz de Fora, Cidade Universitária, São Pedro, 36036-900, Juiz de Fora MG, Brasil

Recebido em 17/04/2018; aceito em 18/07/2018; publicado na web em 31/07/2018

\begin{abstract}
RECENT ADVANCES IN ORGANIC REACTIONS CATALYZED BY NICKEL. Nickel complexes have been widely used as catalysts in organic reactions. Their low price compared to Pd and Pt complexes, in addition to their high reactivity and affinity to $\varpi$ systems; the possibility to access different oxidation states and the difficulty to undergo beta-hydride elimination are important features that have attracted the attention of chemists in recent decades. Furthermore, some drawbacks observed with Pd catalysis have been solved by Ni catalysis. These Ni based-catalysts have been used in different reaction manifolds to promote challenging transformations. Herein, recent work using nickel catalysts in different types of reactions, such as carbonylations, carboxylations, $\mathrm{C}-\mathrm{H}$ activations and dual catalytic systems are described. Critical mechanistic investigations, as well as synthetic applications are also covered.
\end{abstract}

Keywords: nickel; homogeneous catalysis; organic reactions

\section{INTRODUÇÃO}

\section{Aspectos históricos}

O níquel foi descoberto em 1751 e o seu nome foi derivado do alemão Kupfernickel, pois acreditava-se que o minério de níquel continha cobre. Porém, após sua extração, não foi possível observar o cobre, então o nomearam de níquel, o malvado demônio. ${ }^{1}$

Em 1890, Mond observou um diferente comportamento no níquel: o metal reagia com $\mathrm{CO}$ a temperatura ambiente, formando o $\mathrm{Ni}(\mathrm{CO})_{4}$, um composto extremamente tóxico, líquido, com baixo ponto de ebulição. Esse composto foi muito utilizado para purificar o níquel, dos demais metais. ${ }^{1}$

O ganhador do prêmio Nobel, Paul Sabatier, em 1922, fez várias observações sobre o níquel e até o comparou a um "cavalo espirituoso", por ser delicado, difícil de controlar e incapaz de sustentar um trabalho. Porém, ao mesmo tempo, descrevia que ao modificar as condições de preparo do catalisador, poderia ser produzido um outro "tipo de níquel" domável, e esse níquel poderia fazer todo tipo de trabalho e manter sua atividade por muito tempo. Sabatier desenvolveu a primeira hidrogenação de etileno utilizando o níquel. Outro cientista que muito contribuiu para a química de organoníquel foi Wilke. Ele explorou a estrutura e reatividade de diferentes complexos como por exemplo o $\mathrm{Ni}(\mathrm{COD})_{2}$ e investigou reações de oligomerização de olefinas. ${ }^{1}$

O desenvolvimento de reações de acoplamento cruzado, reações com alcenos e alcinos, alilação nucleofílica, oligomerização, cicloisomerização e acoplamento redutivo catalisadas por níquel foi extensamente explorada na década de $70 .^{2}$

\section{Aspectos gerais sobre o Níquel}

O níquel, muitas vezes, é visto apenas um substituto mais barato em relação ao paládio na catálise por metais de transição. Afinal de contas, o uso do paládio como catalisador em reação de acoplamento cruzado já foi premiado com o prêmio Nobel de 2010 e tem sido amplamente utilizado. Apesar disso, o número de publicações

*e-mail: giovanni.amarante@ufjf.edu.br envolvendo catálises por níquel tem crescido cada vez mais em reações de acoplamento cruzado de eletrófilos (haletos e pseudo haletos) e com carbonos nucleofílicos (compostos organometálicos). ${ }^{2}$

As espécies de níquel demonstram uma excepcional habilidade de se coordenar a moléculas orgânicas insaturadas nas reações. Essa coordenação com o centro do níquel o "ativa" e o torna reativo. Outra habilidade do níquel, recentemente revelada com o desenvolvimento da nanotecnologia, é a mediação de transformações de sistemas eletrônicos $\pi$. Nos últimos anos, mais de 40000 artigos foram publicados e tem demonstrado o potencial da catálise por níquel. ${ }^{2}$

A formação e a quebra de ligações C-C requerem ferramentas especiais, como por exemplo, a catálise por metais de transição. Isso se deve a forte ligação que há entre os carbonos. A ligação fraca formada entre metal e carbono (M-C) fornece a base necessária para a transformação catalítica. A energia de dissociação da ligação C-C muda de $87,4 \mathrm{kcal} \mathrm{mol}^{-1}$ para valores mais baixos entre $38 \mathrm{e}$ $66,5 \mathrm{kcal} \mathrm{mol}^{-1}$ para M-C (Tabela 1$){ }^{2}$

Tabela 1. Energia de Dissociação das Ligações (EDL) em etanol e em complexos $\mathrm{L}_{2}(\mathrm{X}) \mathrm{M}^{\mathrm{II}}-\mathrm{CH}_{3}(\mathrm{M}=\mathrm{Ni}, \mathrm{Pd}, \mathrm{Pt})$

\begin{tabular}{cc}
\hline Ligação & EDL, $\mathrm{kcal} \mathrm{mol}^{-1}$ \\
\hline C-C & 87,4 \\
Ni-C & $38,0-51,1$ \\
Pd-C & $48,3-55,2$ \\
Pt-C & $60,8-66,5$ \\
\hline
\end{tabular}

Como pode ser observado pela tabela entre os metais do grupo 10, a força da ligação muda na ordem C-Ni $<$ C-Pd $<$ C-Pt. Dessa forma, explica-se sua alta reatividade em relação a platina. Por um lado, é uma vantagem sua grande reatividade, por outro, o sistema catalítico pode se tornar difícil de controlar. ${ }^{2}$

O Níquel é um metal de transição relativamente eletropositivo, dessa forma, a adição oxidativa, que resulta na perda de densidade eletrônica em torno do níquel, tende a ocorrer relativamente fácil. Como o níquel é mais eletropositivo do que o paládio, a adição oxidativa, que ocorre no acoplamento com eletrófilos, tende a ocorrer consideravelmente mais fácil com a catálise de $\mathrm{Ni}$ do que por $\mathrm{Pd}$, 

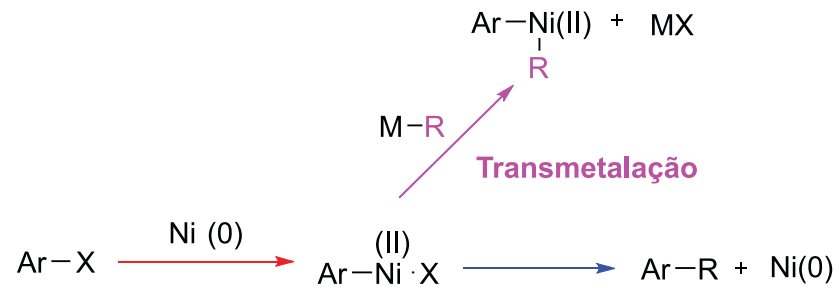

Adição Oxidativa $\backslash$ Eliminação Redutiva

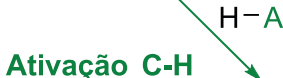

$$
\begin{aligned}
& \mathrm{R}-\underset{\mathrm{I}}{\mathrm{Ni}(\mathrm{II})}+\mathrm{HX} \\
& \mathrm{Ar}
\end{aligned}
$$

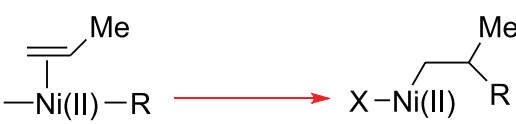

Inserção $\beta$-migratória

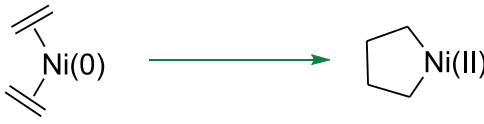

Ciclização oxidativa

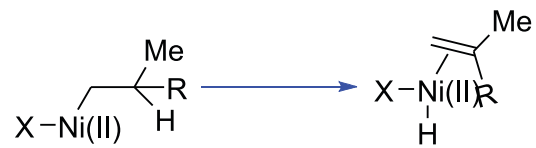

$\beta$-eliminação de hidreto

Figura 1. Etapas das reações com seus respectivos números de oxidação encontradas na catálise de Níquel

como em derivados de fenóis ${ }^{3}$, nitrilas aromáticas ${ }^{4}$ e até mesmo fluoretos de arila ${ }^{5}{ }^{1}$

Porém, consequentemente, a eliminação redutiva ocorre mais facilmente nas reações catalisadas por Pd, por ele ser mais eletronegativo do que o Ni, e facilitar a eliminação.

O número de oxidação do níquel também é mais diversificado do que o do paládio. A maioria das reações catalisadas por esse metal tem como número de oxidação $\mathrm{Pd}(0) / \mathrm{Pd}(\mathrm{II})$ em seu ciclo catalítico, e é mais frequente encontrá-lo em um mecanismo iônico (ou seja, não radicalar). Da mesma forma, ciclos catalíticos com espécies $\mathrm{Ni}(0) / \mathrm{Ni}(\mathrm{II})$ são amplamente encontrados, porém, a fácil acessibilidade a estados de oxidação de $\mathrm{Ni}(\mathrm{I})$ e $\mathrm{Ni}$ (III) permite diferentes reatividades e mecanismos radicalares. Assim, é possível observar muitas reações baseadas em $\mathrm{Ni}(\mathrm{I}) / \mathrm{Ni}(\mathrm{III}), \mathrm{Ni}(0) / \mathrm{Ni}(\mathrm{II}) / \mathrm{Ni}(\mathrm{I})$, e até mesmo ciclos onde o níquel permanece com $\mathrm{Ni}(\mathrm{I})$ durante todo o ciclo catalítico (Figura 1$){ }^{2}$

A $\beta$-eliminação de hidreto tende a ser mais devagar com o níquel, quando comparado ao paládio, pois a barreira de energia da rotação da ligação Ni-C anterior a $\beta$-eliminação de hidreto é significantemente mais alta para o níquel do que para as espécies de paládio, devido a menor eletronegatividade do níquel. (Figura 2).

Além disso, o preço do $\mathrm{NiCl}_{2}$ é de 0,376 reais mmol $^{-1}$ 6, enquanto o $\mathrm{PdCl}_{2}$ é de 21,784 reais $/ \mathrm{mmol}^{6}$ e o de $\mathrm{PtCl}_{2}$ é de 120,937 reais $\mathrm{mmol}^{-16^{6}} .^{2} \mathrm{O}$ níquel também tem um pequeno raio atômico ${ }^{7}$ de $1,24 \AA$, enquanto o do paládio é de $1,39 \AA$ A, e o comprimento da ligação ${ }^{8} \mathrm{Ni}$-ligante é relativamente curto quando comparada com a do Pd-ligante, por exemplo, C-Ni é de 1,82 Å, enquanto a C-Pd é de 2,27 ̊̊ (Figura 2).

Diante de todas essas características, os pesquisadores têm desenvolvido diversas novas reações envolvendo a catálise com níquel. Esse artigo de revisão abordará apenas alguns exemplos recentes (ente 2016 e 2018) relacionados a catálise por níquel em reações de ativação
C-H, carboxilação, carbonilação e sistemas de catálise dupla entre Ni/ fotocatalisadores, por serem assuntos atuais, que podem contribuir de maneira positiva para a sociedade química.

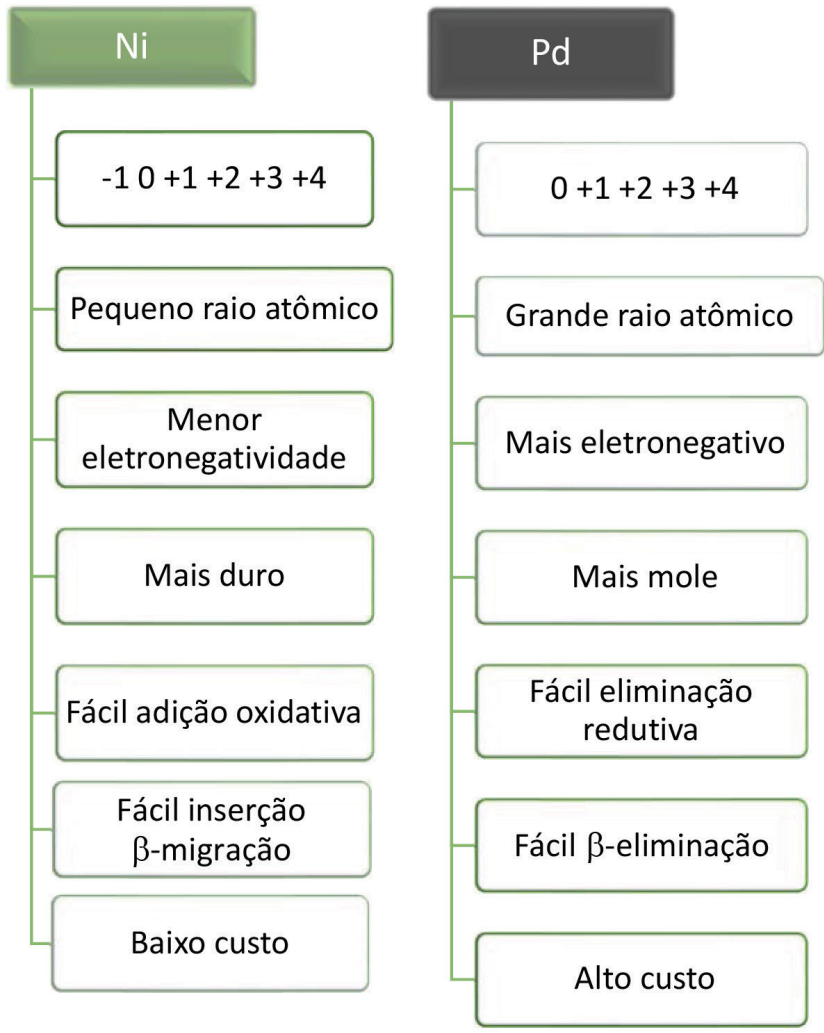

Figura 2. Diferenças entre Níquel e Paládio 


\section{REAÇÕES DE ACOPLAMENTO}

Dentre as diversas descobertas na área científica nos últimos tempos, o uso do níquel como catalisador para reações de acoplamento cruzado, foi muito importante, sendo uma das mais poderosas ferramentas desse tipo de reação, que se mostrou bastante efetiva, principalmente nas reações de Suzuki-Myaura e Negishi. ${ }^{1}$ Porém, seu uso não ficou restrito a essas aplicações, novos sistemas utilizando a catálise por níquel ${ }^{9}$ foram desenvolvidas como pode ser observada a seguir.

\section{Reações de carbonilação}

Skrydstrup e colaboradores, recentemente descreveram uma metodologia para a reação de ${ }^{11} \mathrm{C}$-acetilação de $N$-terminais e $N$-lisinas em peptídeos através de um acoplamento carbonilativo catalisado por paládio, empregando $\left[{ }^{11} \mathrm{C}\right] \mathrm{CO}$ (Esquema 1). Porém, neste caso, apenas produtos acetilados com substituintes metilas foram obtidos. Complexos de paládio com substituintes alquílicos contendo cadeias carbônicas mais longas não foram utilizadas. Talvez, por falta de estabilidade desses complexos, visto que estes sofrem $\beta$-eliminação de hidreto facilmente. ${ }^{10}$

Porém, pouco depois, Skrydstrup descreveu uma metodologia de carbonilação similar, utilizando complexos de níquel. ${ }^{11,12} \mathrm{O}$ uso de níquel permitiu a obtenção de complexos acilados com cadeias maiores, com intuito de realizar o primeiro acoplamento carbonilativo entre nucleófilos e eletrófilos $\mathrm{sp}^{3}$. Os complexos foram utilizados devido à forte ligação dos três nitrogênios ligados ao metal central, prevenindo, assim, ligações de múltiplas unidades de $\mathrm{CO}$ com alguns intermediários reativos, além de impedir a $\beta$-eliminação de hidreto, que ocorre facilmente com o paládio.

Assim, foi reportado o uso desses complexos para o acoplamento cruzado de Negishi, entre reagentes de zinco com brometos de benzila, em atmosfera de $\mathrm{CO}$, pelo uso do sistema de duas câmaras. A viabilidade dessa metodologia é um desafio, já que é um grande problema encontrado nas reações de carbonilação catalisadas por paládio, devido a inerente tendência dos complexos alquila de paládio de sofrerem $\beta$-eliminação de hidreto. ${ }^{13}$

Primeiramente foi investigado uma série de complexos de níquel(II) e sua habilidade para mediar uma sequência de etapas de reações (Esquema 2). Essas etapas consistem em transmetalação com reagentes organometálicos, seguido pela inserção migratória de ${ }^{13} \mathrm{CO}$ para a produção de espécies de acil-níquel. O NiL1 foi selecionado como o mais promissor. Para converter esses experimentos estequiométricos em um protocolo catalítico, uma série de reações entre esse ligante e o acoplamento carbonilativo entre $\mathrm{BnBr}$ e $\mathrm{NPr}-\mathrm{ZnBr}$ foi realizada. Para esse propósito foi utilizado o sistema de duas câmaras, onde o gás CO é gerado em velocidade controlada de um sólido precursor, de modo a limitar a exposição ao sistema catalítico por excesso de CO. Após otimizar as condições reacionais, um escopo de substratos foi avaliado (Esquema 3). Em geral, diversas funcionalidades no anel aromático do brometo de benzila foram bem toleradas, sem precisar alterar as condições reacionais, gerando cetonas com rendimentos que variaram entre boas e excelentes (entre 45 e 94\%). Compostos isotopicamente marcados $\mathrm{com}^{13} \mathrm{C}$ foram obtidos. Alguns reagentes de alquil zinco também foram testados no acoplamento com brometo de 4-terc-butilbenzil sobre as mesmas condições, com um aumento de NiL1. Os produtos puderam ser obtidos com rendimentos que variaram entre $47-90 \%$.

Um mecanismo foi proposto para a reação (Esquema 4). O ciclo se inicia com a transmetalação do complexo de níquel $\mathbf{1 4}$, gerando o complexo alquílico de níquel(II) $\mathbf{1 5}$, o qual sofre inserção de CO para obter o correspondente complexo acil de níquel(II) 16. A transferência de um único elétron (SET) do eletrófilo para o complexo 16 gera o complexo de níquel(III) $\mathbf{1 7}$ e um radical benzílico. A recombinação do radical com uma segunda espécie acil de níquel(II) 16, gera o formal complexo acil alquila de níquel(III) 18, o qual sofre eliminação redutiva, gerando o produto, enquanto forma espécies de níquel(I) 19. A comproporcionação com $\mathbf{1 7}$ gera os dois complexos de níquel(II) 14 e 16, que podem recomeçar o ciclo catalítico. Alguns experimentos foram ainda executados, suportando dessa forma o mecanismo proposto.

\section{Reações de carboxilação catalisadas por níquel}

Atualmente a comunidade química tem voltado suas atenções para o desenvolvimento de metodologias sintéticas que envolvem o uso de $\mathrm{CO}_{2}$ devido ao impacto negativo gerado por esse gás ao ambiente. $\mathrm{O} \mathrm{CO}_{2}$ é um reagente ideal pois é relativamente atóxico e infinitamente abundante. $\mathrm{O}$ grande desafio para o uso de dióxido de carbono é sua alta estabilidade cinética e termodinâmica. Porém, pesquisadores tem investigado métodos baseados na catálise de metais de transição para superar essas adversidades. O uso do níquel como catalisador nas reações de carboxilação ${ }^{14}$, vem sendo explorados nos últimos anos por alguns grupos de pesquisa, como exemplo, o grupo de Martin ${ }^{15}$ e de Tsuji ${ }^{16}{ }^{17}$

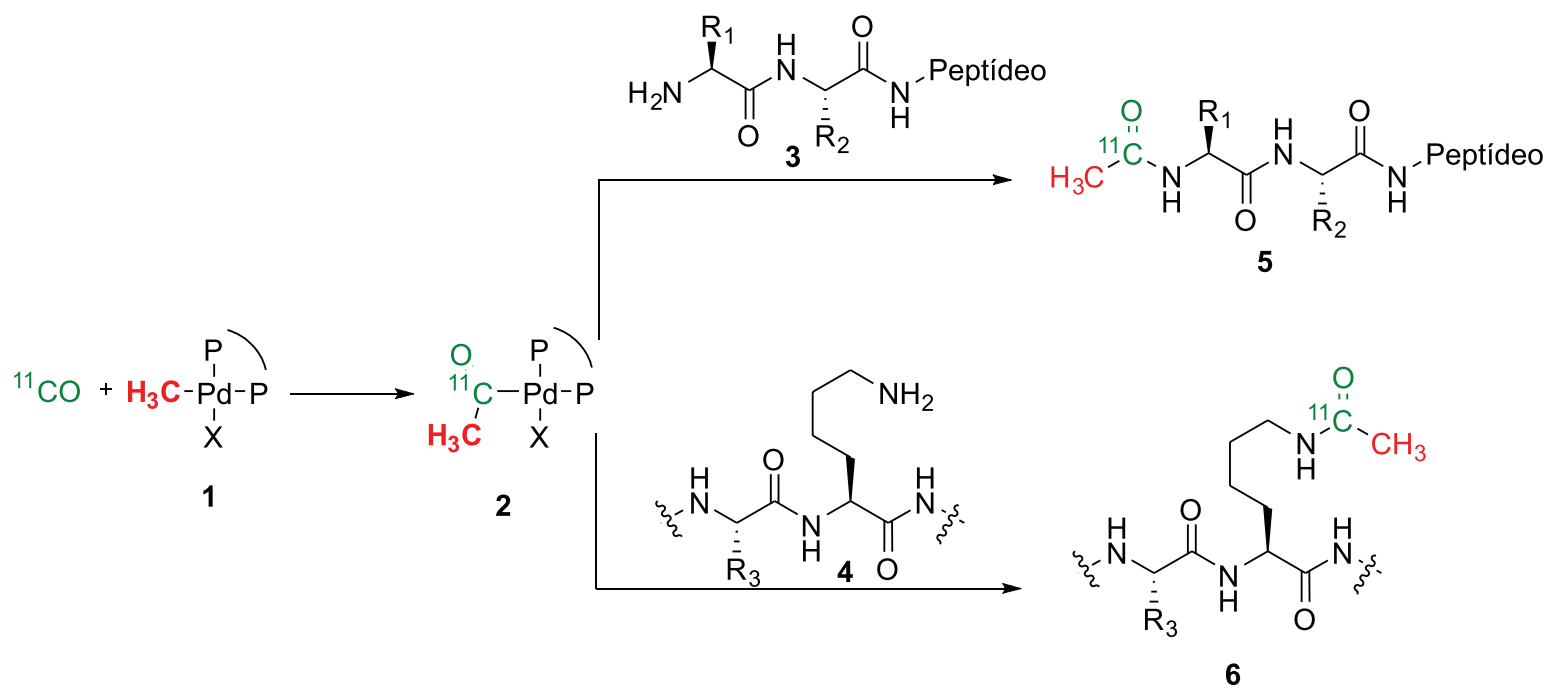

Esquema 1. Estratégia para $\mathrm{N}^{11} \mathrm{C}$-acetilação de aminas terminais e lisinas residuais 


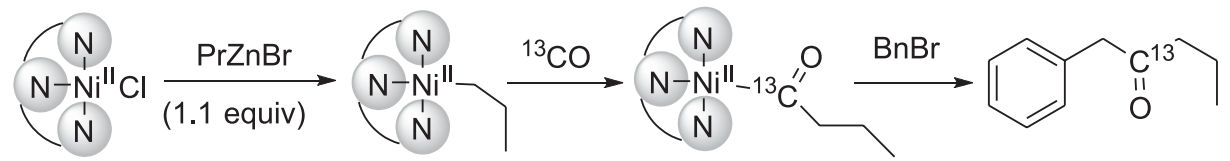

Esquema 2. Sequencia reacional estequiométrica em CO da reação de carbonilação catalisada por níquel
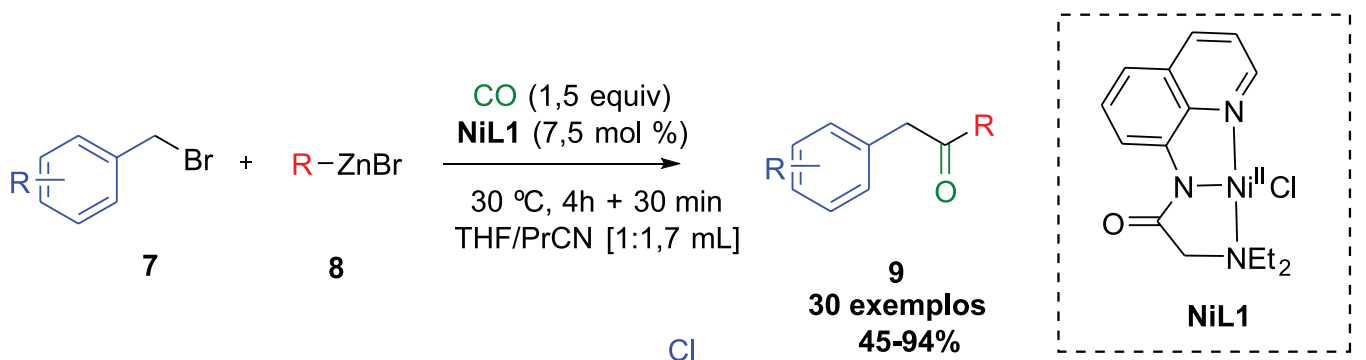<smiles>CCCC(=O)Cc1ccc(C(C)(C)C)cc1</smiles>

10<smiles>CCCC(=O)Cc1ccc(C)cc1</smiles>

11<smiles>CCCC(=O)Cc1c(Cl)cccc1Cl</smiles>

12<smiles>CC(C)(C)c1ccc(CC(=O)CC2CCCC2)cc1</smiles>

13

$94 \%$ $\mathbf{9 0 \%}$

$\mathbf{8 9} \%$

$\mathbf{9 0 \%}$

Esquema 3. Reações de acoplamento carbonilativo entre reagentes alquílicos de zinco com brometos benzílicos catalisados por complexos de níquel

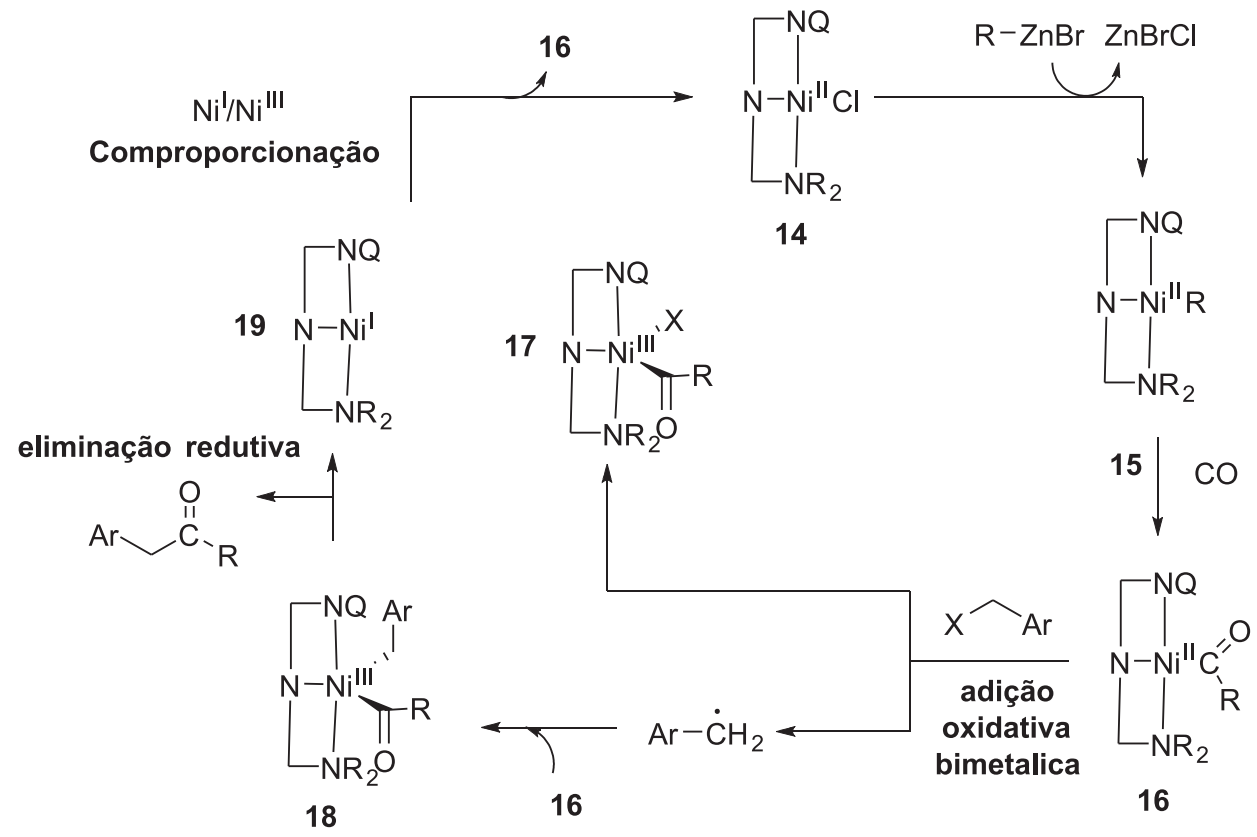

Esquema 4. Ciclo catalítico da reação de acoplamento carbonilativo entre reagentes alquílicos de zinco com brometos benzílicos catalisadas por complexos de níquel

Um mecanismo geral para as reações de carboxilação catalisadas por níquel pode ser proposto, mesmo que o uso de diferentes ligantes em cada sistema possa influenciar um pouco (Esquema 5). O ciclo catalítico inicia-se com a redução do complexo de $\mathrm{Ni}(\mathrm{II})$ a $\mathrm{Ni}(0) \mathbf{2 0}$, seguido por uma transferência de um único elétron (SET) do haleto de alquila, para formar o transitório radical alquila 21 e espécies de haleto de $\mathrm{Ni}(\mathrm{I}) \mathbf{2 2}$. A recombinação e subsequente redução pelo manganês(0), produz a espécie reativa $\eta 1-\mathrm{Ni}(\mathrm{I}) \mathbf{2 3}$, que sofre inserção de $\mathrm{CO}_{2}$, gerando 24. A redução mais uma vez do manganês (0), permite o ciclo catalítico recomeçar e formar carboxilato de manganês $\mathbf{2 5}$, o qual é hidrolisado durante o término da reação, gerando o ácido carboxílico $26 .^{18}$

Na literatura é possível encontrar protocolos para carboxilação de haletos primários, porém a extensão para secondários e terciários ainda é um desafio. Reações em um anel tenso e no orbital reibridizado, como nos anéis de ciclopropilas podem facilitar a carboxilação de ciclopropil secundários, levando assim a um novo acesso a ácidos ciclopropil carboxílicos. Pensando nesse desafio, Martin e colaborados descreveram uma metodologia, utilizando condições brandas na presença de $\mathrm{CO}_{2}$, a uma pressão atmosférica (Esquema 6). É a primeira carboxilação redutiva catalítica de haletos orgânicos secundários que podem ser conduzidos na ausência de componentes- $\pi$ adjacentes. Curiosamente, diferentes perfis de estereosseletividades foram encontradas quando diferentes haletos ou ciclopropanos foram empregados. Os produtos foram obtidos com rendimentos que variaram entre 47 e $79 \%$. Foi observado que a presença de substituinte aromático é imprescindível para a reação ocorrer. Todas as reações assimétricas foram obtidas na forma de mistura cis/trans, sendo que o 


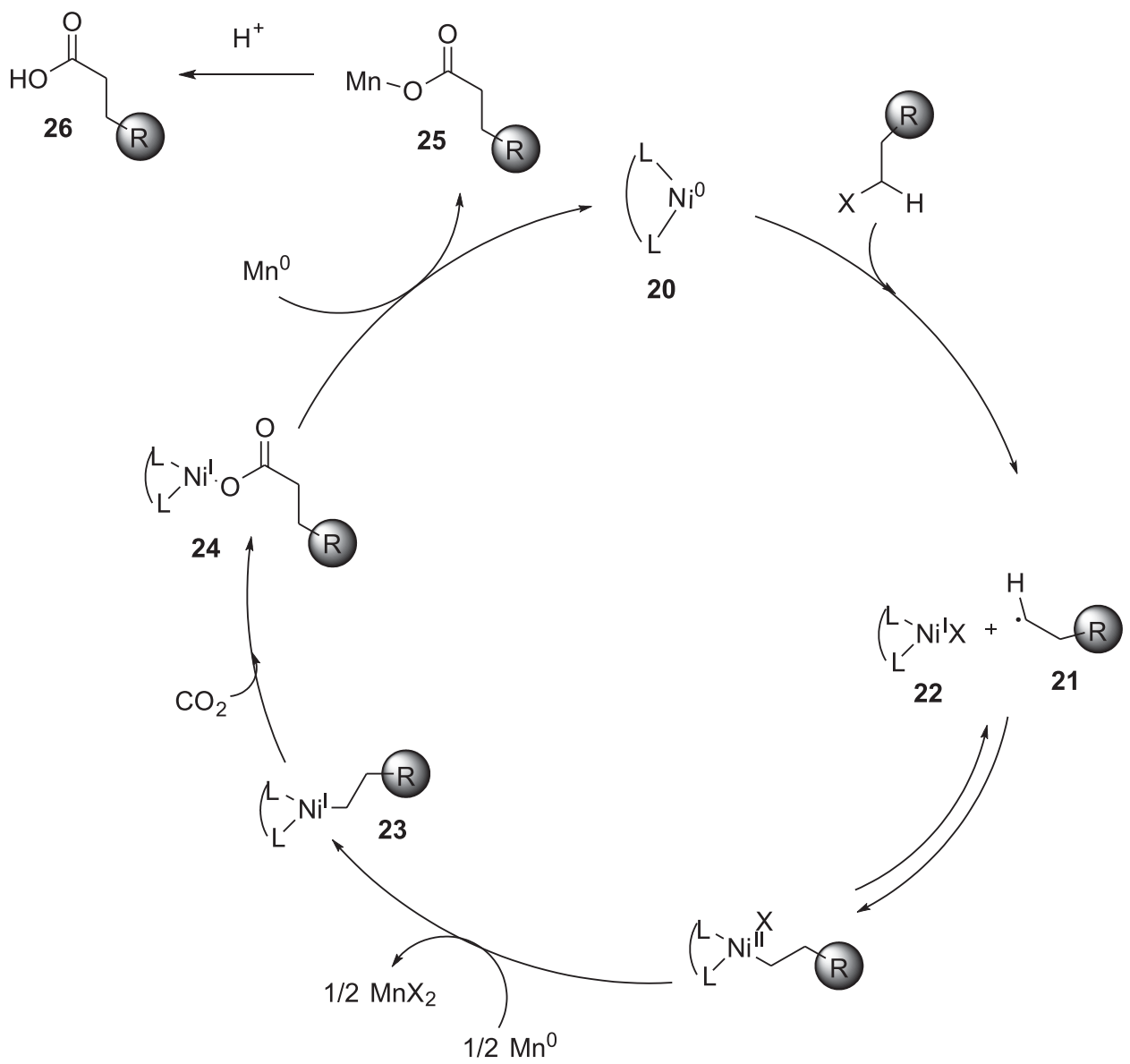

Esquema 5. Mecanismo geral para reação de carboxilação catalisada por níquel.

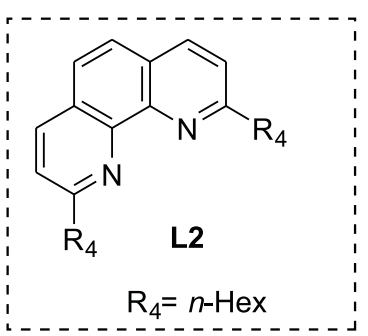

1.1:1- $5: 1$ rd

Esquema 6. Carboxilação de brometos de ciclopropila

isômero majoritário continha a geometria trans. Foi observado ainda que a relação cis/trans obtida nos produtos não se correlacionava bem com as do material de partida, sugerindo dessa forma, que o intermediário reagiria com radicais. ${ }^{18}$

Em seguida, foi investigado a possibilidade dos ciclopropanos promoverem uma reação análoga a hidrocarboxilação com um perfil de alta estereosseletividade. Alterando algumas condições, como o uso de $\mathrm{Ni}(\operatorname{cod})_{2}$ (bis(1,5-ciclooctadieno) niquel(0)) como fonte de nitrogênio, foi possível obter produtos com rendimentos moderados, porém com alta diastereosseletividade (Esquema 7). Foi observado, de forma majoritária, a geometria trans para esses compostos. Enquanto a intermediação do hidreto de níquel pode ser justificada do baseado no uso de $\mathrm{MePhSiH}$, o sucesso da utilização de $\mathrm{Et}_{3} \mathrm{Al}$ nessa carboxilação pode sugerir a intermediação de niquelactonas seguida por uma subsequente transmetalação//3-eliminação de hidreto. ${ }^{18}$

Pouco depois, o mesmo grupo investigou o estabelecimento de uma metodologia para promover a carboxilação de álcoois simples catalisada por níquel, na ausência de reagentes organometálicos em

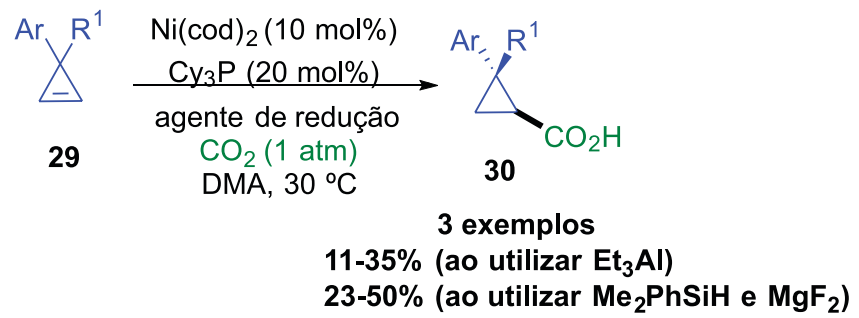

Esquema 7. Hidrocarboxilação de ciclopropenos

quantidades estequiométricas e sensíveis ao ar. Assim, foi discutida a hipótese de que $\mathrm{CO}_{2}$ poderia ter duas funções, como fonte de $\mathrm{C}_{1} \mathrm{e}$ como um grupo de ativação para clivagem de ligação $\mathrm{C}-\mathrm{O}$ (Esquema $8)$. A hipótese é sustentada pela habilidade do $\mathrm{CO}_{2}$ de reagir reversivelmente com álcoois para formar ácidos carboxílicos, diminuindo assim, a energia de ativação que promove a cisão $\mathrm{C}-\mathrm{O}$, enquanto aumenta a velocidade da adição oxidativa do $\left[\mathrm{Ni}^{0} \mathrm{~L}_{\mathrm{n}}\right](\mathrm{Ln}=$ ligante), anterior a inserção de $\mathrm{CO}_{2}$. Dessa forma, os autores desenvolveram 
uma metodologia para a carboxilação de álcoois alílicos, catalisadas por níquel, sob pressão atmosférica. A metodologia foi analisada utilizando dois ligantes diferentes, $\mathbf{L 3}$ e L4. Foi observada uma peculiar seletividade, onde o ligante deveria ser utilizado de acordo com o substrato. Substratos ramificados funcionavam bem com o ligante L4 e os substratos lineares funcionavam bem com o ligante L3. A presença de C-O eletrofílicos, que poderia ser susceptível ao acoplamento cruzado por níquel, como aril metil ésteres e aril pivalatos não competiram com a reação de carboxilação. Centros quaternários e terciários foram ainda acessados utilizado a metodologia. Os produtos foram obtidos com rendimentos que variaram entre 54 e $92 \%$. Um produto natural foi sintetizado, a cognac lactona (Esquema 9), a fim de demonstrar a aplicabilidade da metodologia. ${ }^{19}$

Visando entender a função do ligante, foram feitas algumas investigações da reatividade das espécies de $\left[\mathrm{Ni}^{0} \mathrm{~L}_{\mathrm{n}}\right]$ (Esquema 10). Foi observado a falta de reatividade quando o álcool alílico $\mathbf{3 8}$ foi exposto a quantidades estequiométricas de $\left[\mathrm{Ni}^{0}(\mathbf{L 3})\right]$ ou $\left[\mathrm{Ni}(\mathrm{COD})_{2}\right] /$ L4 na ausência de $\mathrm{CO}_{2}$, reforçando a ideia que a adição oxidativa do álcool para o $\left[\mathrm{Ni}^{0} \mathbf{L n}\right]$ não ocorre. Enquanto o $\left[\mathrm{Ni}^{0}(\mathbf{L} 3)_{2}\right]$ requer a presença de $\mathrm{Zn}$ na rota para formar $\mathbf{4 0}$, o correspondente $\left[\mathrm{Ni}(\mathrm{COD})_{2}\right] /$ L4 produz o produto 39 na ausência do redutor. Os resultados sugerem que há uma intermediação do intermediário $\eta^{1}-\mathrm{Ni}^{\mathrm{I}}$ com o ligante bidentado rígido $\mathbf{L 3}$, levando a inserção de $\mathrm{CO}_{2}$ no átomo de carbono $\alpha$. Por outro lado, a presença do ligante tridentado $\mathbf{L} \mathbf{4}$ pode resultar em um intermediário $\eta^{1}-\mathrm{Ni}^{\mathrm{II}}$, que levará a formação da ligação $\mathrm{C}-\mathrm{C}$ no carbono $\gamma{ }^{19}$

Recentemente, o grupo de Martin investigou a incorporação múltipla de moléculas de $\mathrm{CO}_{2}$ a 1,3-dienos catalisadas por níquel, uma rota elegante para a síntese de ácidos adípicos. Os múltiplos sítios de inserção de $\mathrm{CO}_{2}$ poderiam ser controlados na ausência de fontes de hidreto pela exploração inerente da nucleofilicidade carbogênica de I, como demonstrada no Esquema 11. Sobre um equilíbrio $\pi-\sigma$, os
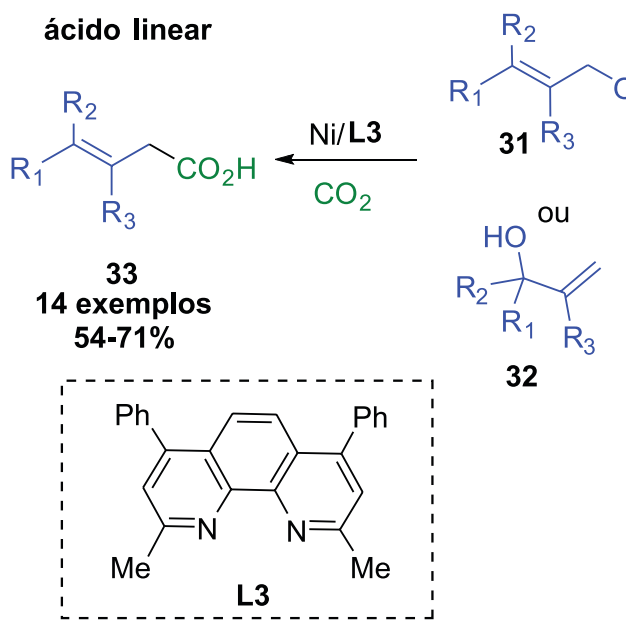

32

Esquema 8. Reação de carboxilação de álcoois alílicos

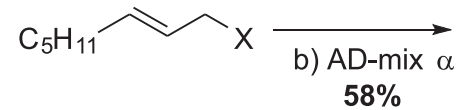

$70 \%\left(\begin{array}{l}\mathrm{X}=\mathrm{OH} 35 \\ \mathrm{X}=\mathrm{CO}_{2} \mathrm{H} 36\end{array}\right.$ $58 \%$ a) $\mathrm{TMSCHN}_{2}$ $\mathrm{C}_{5}$

37

r.e. $=97.5: 2,5$<smiles>O=C1C[C@H](O)[C@H]([SbH2])O1</smiles><smiles>O=C1CC(O)[C@H]([SbH2])O1</smiles>

(+)-trans-cognac lactona

Esquema 9. Síntese total da (+) trans-cognac lactona

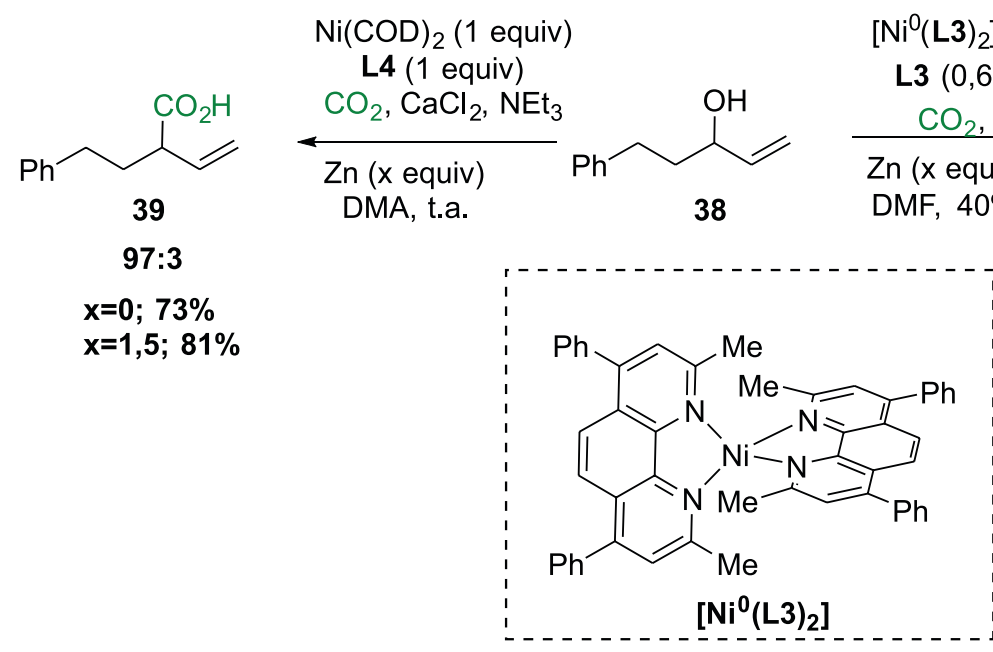

\section{ácido ramificado}<smiles>[R3]C(=C)C([R2])([R])C(=O)O</smiles>

34

14 exemplos $64-92 \%$ 
ácidos adípicos podem ser obtidos por subsequentes incorporações regiosseletivas de $\mathrm{CO}_{2}$ à $\mathbf{I}$, que procede a uma redução para a recuperação de espécies do catalisador $\mathrm{Ni}(0)$ Ln. ${ }^{20}$

Após otimizar as condições reacionais, a generalidade da reação de dicarboxilação foi investigada (Esquema 12). A proteção in situ dos ácidos carboxílicos e a redução de alcenos foi necessária, sem a necessidade de purificação do ácido adípico resultante. Diversos produtos foram obtidos com rendimentos entre 51 e $89 \%$. Butadienos, piperilenos e isoprenos também puderam ser utilizados, gerando produtos com rendimentos entre 61 e $65 \%$ e uma regiosseletividade que variou entre 93:7 e 77:23 (Esquema 13). ${ }^{20}$

Em seguida, foram feitos estudos sobre o mecanismo da reação (Esquema 13). Primeiramente, foi feito a análise da estereoquímica de 46 com $\mathrm{CO}_{2}$. Trans-47 é preferencialmente formado do que cis47, sugerindo que o segundo $\mathrm{CO}_{2}$ é inserido no $\pi$-alil complexo I por um ataque pela face oposta. Porém, essa interpretação não exclui a rápida interconversão dos complexos $\pi$-alil sobre a exposição de $\mathrm{Ni}(0)(\mathbf{L 5})$, anterior a inserção de $\mathrm{CO}_{2}$. Ao analisar o complexo Ni-1, é possível observar que sua reatividade com 41 não é comparável ao com $\mathrm{Ni}(\mathrm{COD})_{2} / \mathbf{L 5}$, pois não é observado nem mesmo traços de $\mathbf{4 8}$. O Ni-2 gerou apenas 48 na presença $L 5$ e Mn. Esses resultados sugerem que o processo de transferência de um elétron (SET) funciona através das espécies de $\mathrm{Ni}(\mathrm{I}){ }^{20}$

\section{Reações de ativação C-H}

As reações de acoplamento catalisadas por níquel também podem ser particularmente úteis em metodologias de ativação C-H. Ainda que alguns exemplos mostraram a mediação por níquel em ativações C-H em 1963, desenvolvimentos catalíticos dessa metodologia vêm sendo publicados mais recentemente. ${ }^{21}$

Nakao e colaboradores, em 2016, desenvolveram um novo método para a alquilação seletiva de benzamidas, e na posição para de cetonas aromáticas, através de uma catálise cooperativa dentre níquel e alumínio. Foi utilizado um sistema co-catalítico volumoso, o MAD (2,6-t- $\left.\mathrm{Bu}_{2}-4-\mathrm{Me}-\mathrm{C}_{6} \mathrm{H}_{2} \mathrm{O}\right)_{2} \mathrm{AlMe}$, que permitiu reações entre alcenos e benzamidas ou cetonas para a formação dos correspondentes produtos para alquilados. Diversos produtos puderam ser obtidos utilizando a metodologia com rendimentos que variaram entre 34 e $97 \%$ e com seletividade entre 78:10:7,5 e >99:1 (Esquema 14). ${ }^{22}$

Reações para determinar a velocidade inicial da reação foram medidas por análise cromatográfica a gás e proporcionou o valor de 3,7 para o efeito isotópico cinético. A reação entre 55 e 56 resultou na perda de deutério, exclusivamente na posição para de $\mathbf{5 0}$ e parcial inserção de deutério da posição $\alpha$ de 56 (Esquema 15). Dessa forma, foi possível inferir a etapa determinante de velocidade e a reversibilidade da ativação $\mathrm{C}-\mathrm{H}$, exclusivamente da posição para $^{22}$

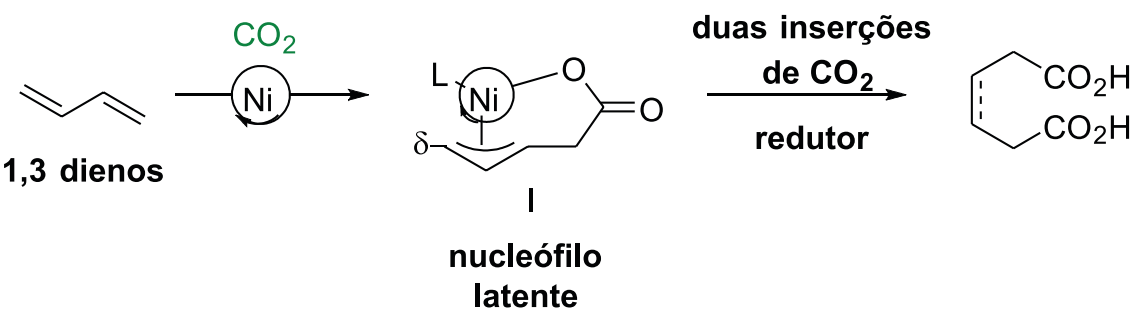

Esquema 11. Carboxilação de 1,3 dienos
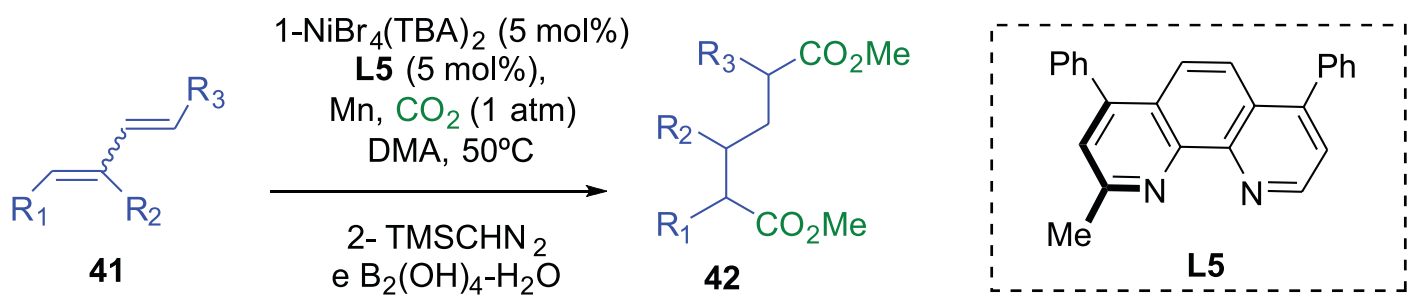

17 exemplos

$51-89 \%$

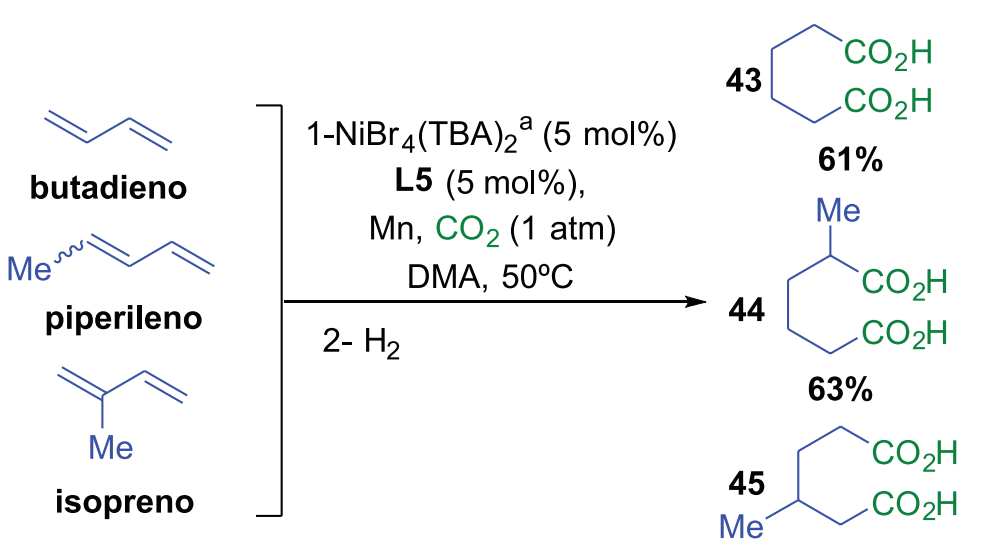

$65 \%$

Esquema 12. Carboxilação 1,4 de 1,3-dienos catalisadas por níquel 
Um pouco depois, o mesmo grupo publicou um trabalho utilizando uma metodologia similar onde foi possível expandir o escopo de substratos, alquilando sulfonil arenos. Produtos com rendimentos que variaram entre $23-83 \%$ foram obtidos com seletividade entre 73:27- >99:1. (Esquema 16). ${ }^{23}$

Foi proposto um ciclo catalítico para a reação que corrobora

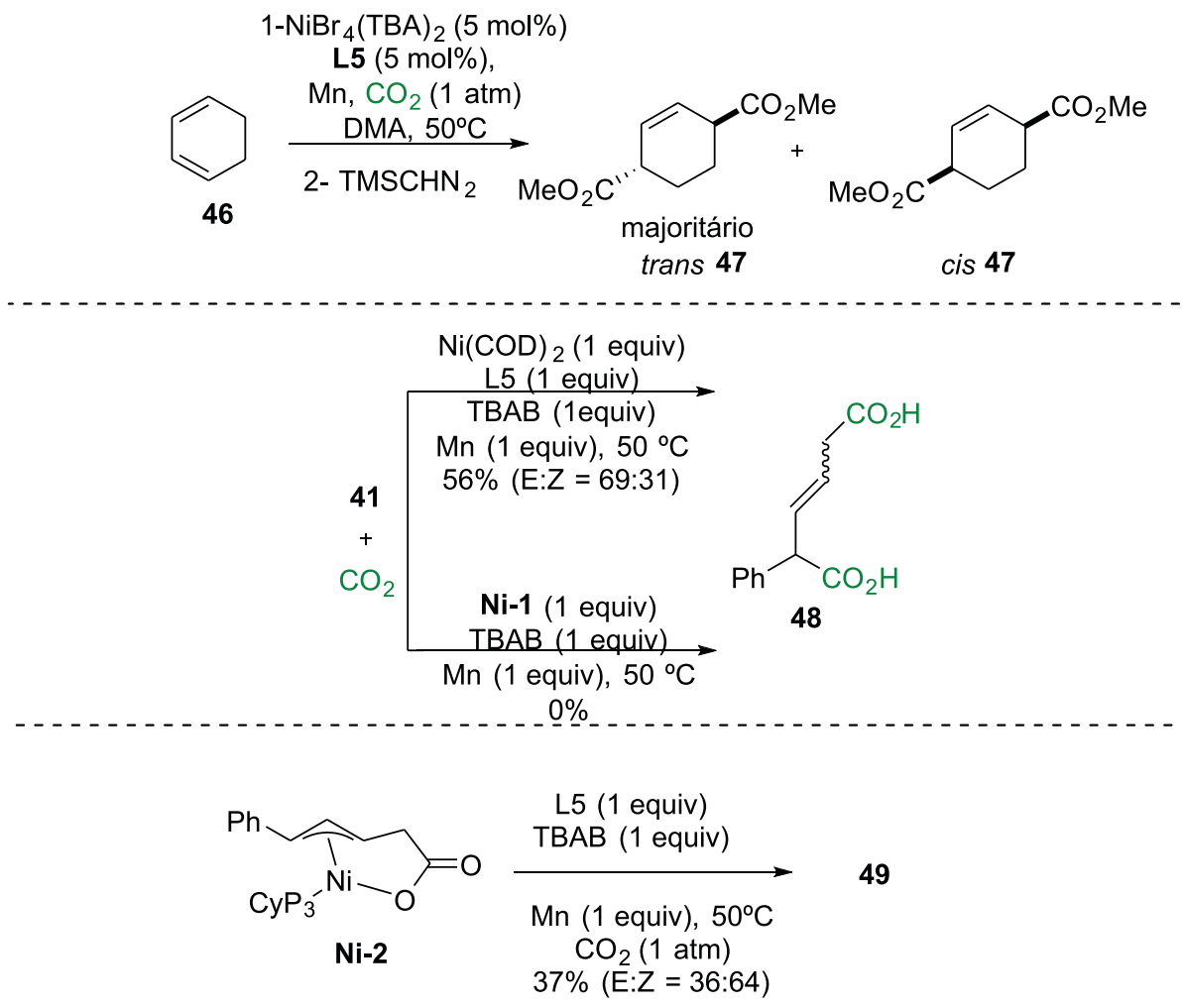

Esquema 13. Experimentos mecanísticos para a reação de carboxilação 1,4 de 1,3-dienos catalisadas por níquel<smiles>[R]NC(=O)c1ccc(-[R]2ccccc2)cc1</smiles>

50

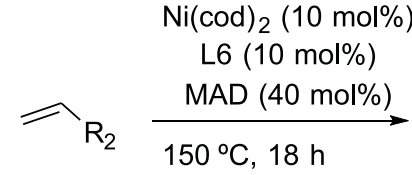

51<smiles>[R2]CCc1ccc(C(=O)N[R])cc1[R]</smiles>

52

18 exemplos

$34-97 \%$

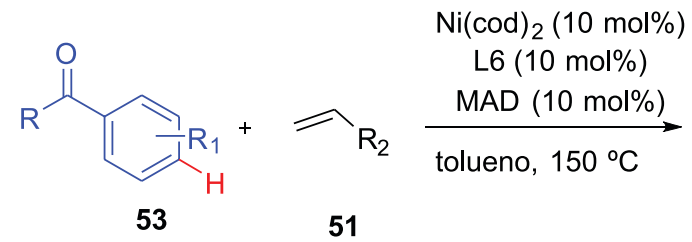<smiles>[R2]CCc1ccc(C([R])=O)cc1[R]</smiles>

54

12 exemplos

$45-91 \%$

94:6- >99:1
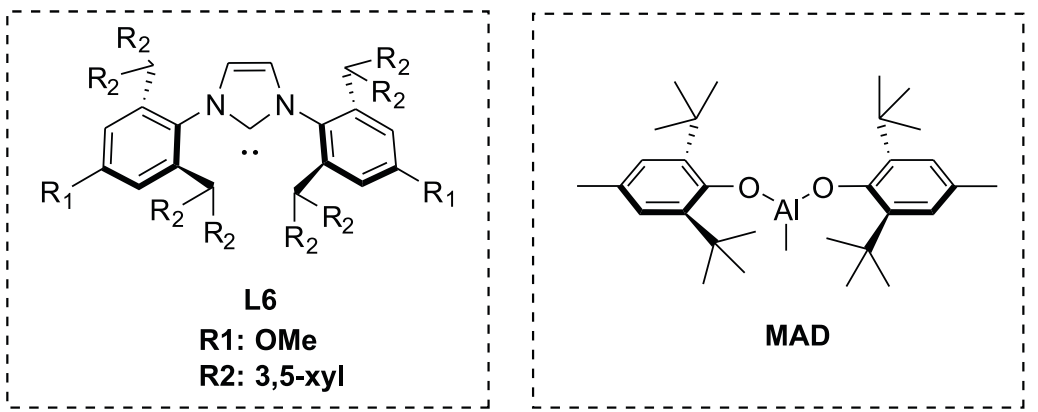

Esquema 14. Alquilação seletiva de benzamidas e cetonas aromáticas 
<smiles>[2H]c1c([2H])c([2H])c(C(=O)NCC)c([2H])c1[2H]</smiles>

$+$<smiles>C=C[AsH2]OCCCC</smiles>

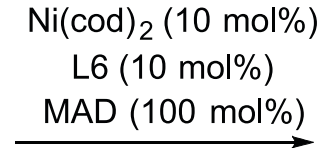

$150^{\circ} \mathrm{C}, 3,5 \mathrm{~h}$

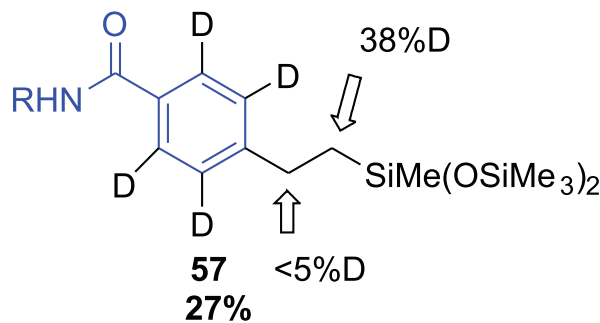

56

\section{Recuperado:}

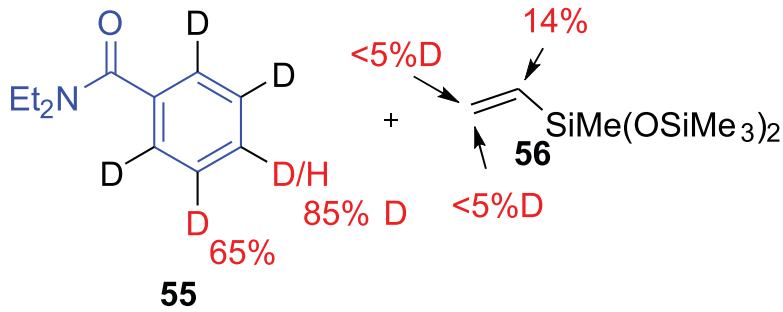

55

Esquema 15. Reação de alquilação utilizando benzamida marcada isotopicamente com deutério

com os cálculos DFT obtidos no trabalho anterior (Esquema 17). Assim, o complexo bis(alceno)níquel(0) $\mathbf{6 1}$ troca de ligante com o aduto sulfonil areno/MAD para formar o complexo 64 através do $\mathrm{Ni}(0)$-ligado-ao-alceno 62 e o complexo- $\pi$ 63. A ligação C-H é clivada e o complexo alquil-Ni(II)-aril 65 é formado através de uma transferência de hidrogênio concertada. Uma isomerização geométrica gera o complexo de Ni(II) 67 em forma de T através de seu isômero 66, antes da eliminação redutiva, que então gera a ligação C-C. O catalisador de alumínio tem como função chave a aceleração e o regiocontrole da etapa da ativação $\mathrm{C}-\mathrm{H}^{23}$

O grupo de Kayani reportou uma investigação sistemática de arilação C-H de oxazóis e benzoxazóis catalisadas por níquel, em relação a influência eletrônica, estérea e a variação do grupo de saída dos eletrófilos fenólicos. O acoplamento do 5-metil benzoxazol com diferentes pivalatos foi explorado primeiramente. Os produtos foram obtidos com rendimentos que variaram entre 44-94\% (Esquema 18), sendo que o rendimento mais baixo foi para o produto mais impedido estericamente, o orto-metilfenil pivalato. Um segundo escopo de pivalatos com diversos azóis foi investigado. Essa transformação se mostrou compatível com éteres, fluoretos, grupos trifluorometil e alquil benzílicos. O efeito eletrônico se mostrou significativo, como por exemplo, em substratos neutros e ricos em elétrons, que conduziram aos produtos em baixos rendimentos. Os produtos desse escopo foram obtidos com rendimentos entre 57 e $94 \%$. Em seguida foi explorado o acoplamento de azóis com tosilatos e mesilatos. O acoplamento de 5-metil benzoxazol com diversos tosilatos resultou em produtos com baixos rendimentos, quando comparados com o correspondente pivalato (entre 27 e $70 \%$ ). Rendimentos um pouco melhores foram observados para os mesilatos (entre 30 e $82 \%$ ). Um escopo utilizando arilação de carbamatos também foi demonstrado<smiles>[R][R]([H])([H])c1ccc([TlH])cc1</smiles>

58

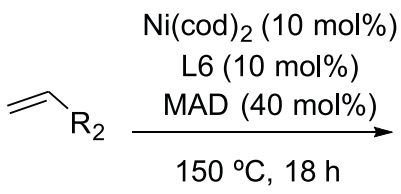

59

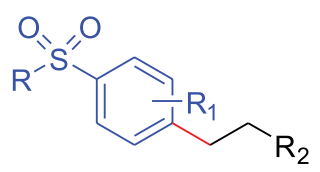

60

15 exemplos

23-83\%

73:27- >99:1
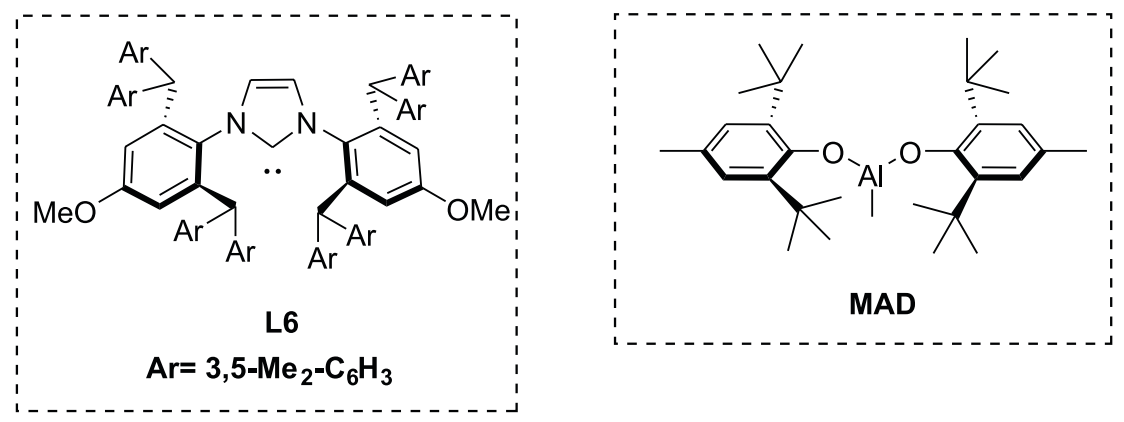

Esquema 16. Alquilação de sulfonil arenos com alcenos por catálise cooperativa entre $\mathrm{Ni} / \mathrm{Al}$ 


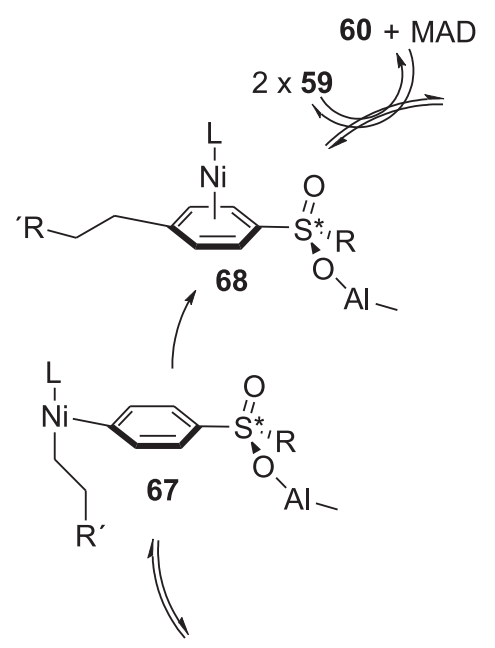<smiles>[R]C=CN(I)C([R])C=CC=CC(=C)C</smiles>

59<smiles>[R]CCN([Tl])c1ccc([S+]([R])(=O)O[AlH]C)cc1</smiles><smiles>[R]C1C[N+](I)(c2ccc([S+]([R])(=O)O[AlH]C)cc2)[C@H]1[R]</smiles>

Esquema 17. Ciclo catalítico proposto para a reação de alquilação de sulfonil arenos

onde rendimentos entre 22 e $83 \%$ foram obtidos. ${ }^{24}$

Um estudo de competição foi ainda realizado para avaliar a reatividade relativa entre diferentes eletrófilos. A reação do 5-metil benzoxazol com quantidades equilmolares de dois eletrófilos eletronicamente similares contendo diferentes grupos abandonadores foram explorados (Esquema 19). Foram comparados o mesilato, o pivalato e o carbamato. Os resultados implicaram que as velocidades relativas de arilação seguem a seguinte ordem: mesilato > pivalato $>$ carbamato. ${ }^{24}$

Miura e colaboradores desenvolveram uma alquilação C-H seletiva de 2-piridonas catalisadas por níquel. Após obter as melhores condições reacionais, foi investigado o escopo de 2-piridonas
(Esquema 20). A presença de grupos retiradores de elétrons, como $\mathrm{CF}_{3}$ na posição $\mathrm{C} 3$ e $\mathrm{C} 4$ foram toleradas, e os produtos foram obtidos com bons rendimentos. Piridonas contendo substituintes com grupos doadores de elétrons apresentaram reatividade moderada. O método foi um pouco sensível a fatores estéreos, e os substituintes no C5 das piridonas não acoplaram com o COD. As piridonas halogenadas foram substratos relutantes, e uma pequena, mas significativa, quantidade de piridonas dehalogenados foi detectada por causa da competitiva da adição oxidativa da ligação halogênio-C em relação a baixa valência do centro do níquel. Os produtos foram obtidos com rendimentos que variaram entre 32 e $90 \%$. A reatividade de alguns alcenos também foi investigada (Esquema 20). O 1,3-dieno e o 1,6-dieno contendo<smiles>Cc1ccc2ocnc2c1</smiles>

69<smiles>[R]Oc1ccc([18OH])cc1</smiles>

$\mathrm{Ni}(\mathrm{COD})_{2}(10 \mathrm{~mol} \%)$ ligante $(20 \mathrm{~mol} \%)$

base (1,5-2,0 equiv) xileno, $140^{\circ} \mathrm{C}$<smiles>Cc1ccc2oc(Br)nc2c1</smiles>

71

10 exemplos 44-94\%
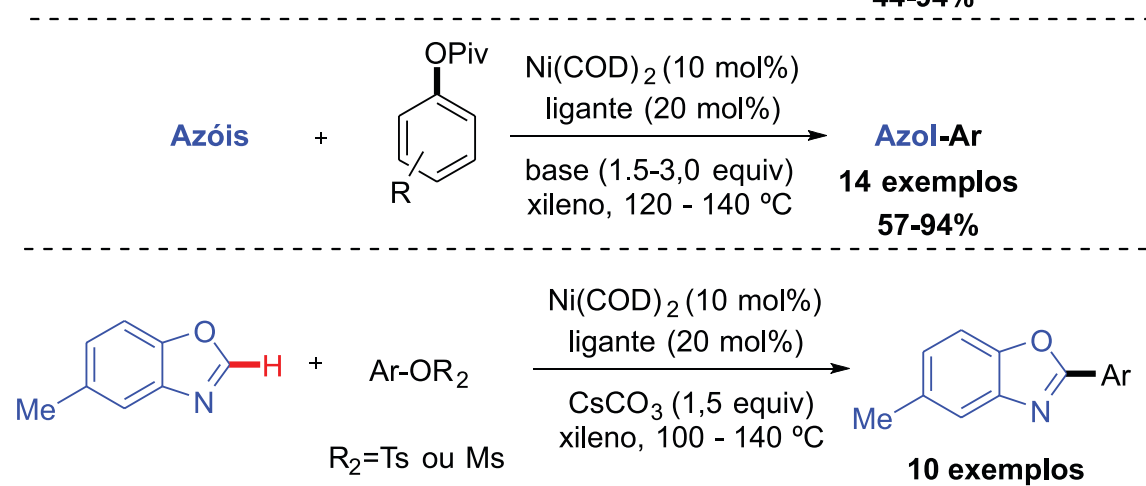

$\mathrm{Ni}(\mathrm{COD})_{2}(10 \mathrm{~mol} \%)$

ligante $(20 \mathrm{~mol} \%)$

$\mathrm{CsCO}_{3}(1,5$ equiv)

xileno, $100-140{ }^{\circ} \mathrm{C}$

$57-94 \%$
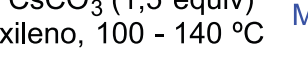


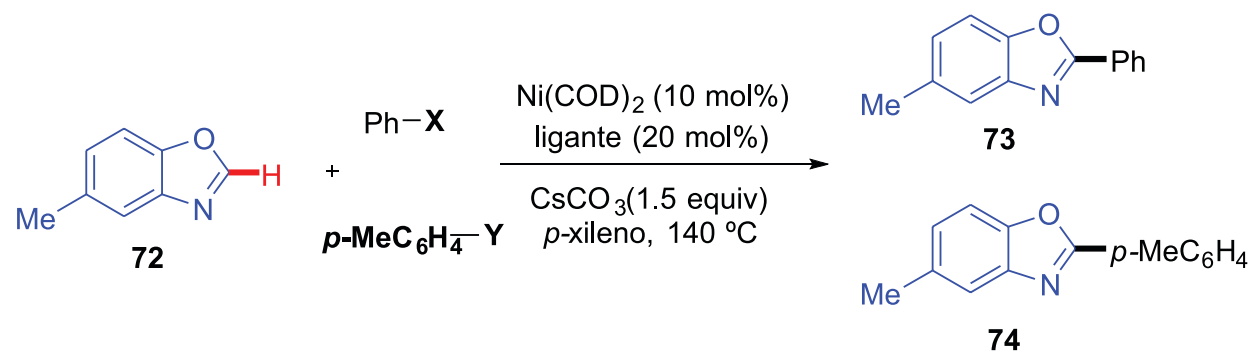

Esquema 19. Reação utilizada nos estudos de competição

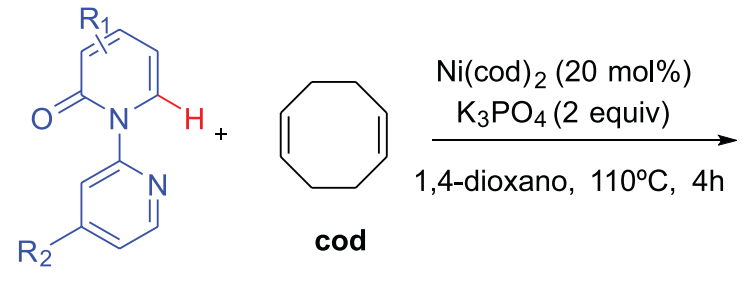

75

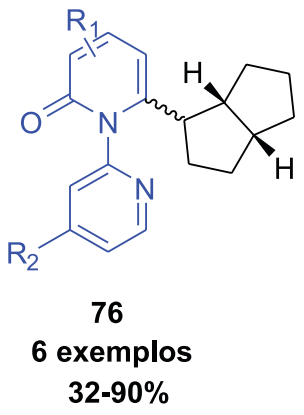

$32-90 \%$

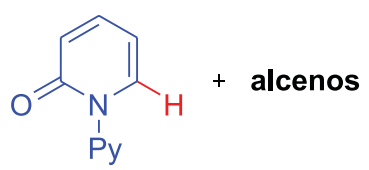

77

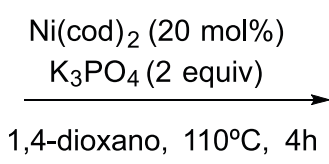

1,4-dioxano, $110^{\circ} \mathrm{C}, 4 \mathrm{~h}$<smiles>[R]c1cccc(=O)n1[12F]</smiles>

78

\section{4 exemplos}

$14-78 \%$

Esquema 20. Alquilação de 2-piridonas com dienos e alcenos ativados

metilenos foram testados, assim como alcenos simples terminais, mas nenhum produto de acoplamento foi detectado. ${ }^{25}$

Experimentos controle com marcação isotópica de deutério de 77- $d_{1}$ e estireno- $d_{8}$ foram executados a fim de determinar o mecanismo da reação. De acordo com essas informações, foi proposto um mecanismo como é apresentado no Esquema 21. O Ni(COD) $)_{2}$ inicialmente liga-se ao 77 e ao estireno para formar o complexo- $\sigma$ tricoordenado de níquel 79, incluindo a ligação $\mathrm{C}-\mathrm{H}$ da posição C-6 da piridona. Subsequente, ocorre a transferência concertada do próton, no qual, a ligação C-H é clivada, e duas ligações C-Ni são formadas. O resultante intermediário $\sigma$-benzil Ni $\mathbf{8 1}$ está em equilíbrio com a estrutura termodinamicamente mais estável $\pi$-benzil Ni 81'. A eliminação redutiva produzida e a coordenação de outro 77 gera o complexo contendo o produto. A troca da ligação final com o estireno, libera a piridona alquilada 78, fechando o ciclo catalítico. Os resultados obtidos com os experimentos controle sugerem que o processo de transferência de um único próton é fácil e reversível, e a eliminação redutiva é etapa determinante da velocidade e é irreversível. Ao otimizar a reação, foi observado o uso indispensável de $\mathrm{K}_{3} \mathrm{PO}_{4}$. A função exata do $\mathrm{K}_{3} \mathrm{PO}_{4}$, não é totalmente esclarecida pelos autores, mas sabe-se que funciona como ligante aniônico adicional para o Ni e acelera a etapa limitante, a eliminação redutiva. ${ }^{25}$

A ativação C-H catalisada por níquel, por um tempo, tornou-se limitada a hidrogênios ácidos. O grupo de Chatani desenvolveu um sistema bidentado quelado ${ }^{26}$ onde é possível ativar hidrogênios não ácidos como está descrito no Esquema 22 (para simplificar o entendimento, as condições e os grupos que não estão envolvidos na etapa chave não foram demonstrados no esquema). Porém, a presença de grupos $\mathrm{N}\left(\mathrm{sp}^{2}\right)$ e $\mathrm{NH}$ eram indispensáveis para a reação proceder. As reações reportadas podem ser classificadas por dois tipos, dependendo do estado de oxidação da espécie catalítica chave. No caso do sistema catalisado por $\mathrm{Ni}(0)$, ocorre a coordenação do átomo de $\mathrm{N}\left(\mathrm{sp}^{2}\right)$ com o centro do $\mathrm{Ni}$, seguido pela adição oxidativa da ligação $\mathrm{N}-\mathrm{H}$. Isso conduz ao complexo 82 e a clivagem da ligação $\mathrm{C}-\mathrm{H}$, que procede através da metátase de ligação $\sigma$, levando a formação do complexo ciclo metalado 83, com geração concomitante de $\mathrm{H}_{2}$. Este por sua vez, pode ser captado por um aceptor de hidrogênio, como um alcino. No sistema catalisado por $\mathrm{Ni}(\mathrm{II})$, ocorre a coordenação do $\mathrm{N}\left(\mathrm{sp}^{2}\right)$ com o centro do $\mathrm{Ni}$, seguido pela troca de ligantes, gerando o complexo 84, o qual, após a clivagem da ligação C-H através do mecanismo de metalação-desprotonação concertada (MDC), gera o ciclo metalado 85. Após a formação dos ciclos metalados 84 e 85, diversos reagentes podem ser utilizados no restante da reação. Independente do mecanismo, a função do átomo de $\mathrm{N}\left(\mathrm{sp}^{2}\right)$ é aproximar o catalisador de níquel da ligação N-H através de uma coordenação, seguida por uma ligação covalente N-Ni via adição oxidativa ou de troca de ligantes. Os átomos de níquel nos intermediários resultantes 82 e 83, não são próximos o suficiente para ativar a orto ligação $\mathrm{C}-\mathrm{H}$, que serão, em seguida, clivadas. Dessa forma, a formação da ligação covalente N-Ni é a chave da ativação $\mathrm{C}-\mathrm{H}$ nesse sistema de quelação bidentada. ${ }^{27}$

Porém, em 2017, Chatani desenvolveu um novo modelo, onde o uso de uma base forte seria capaz de desprotonar a amida, gerando um ânion que facilmente reagiria com o catalisador de níquel, produzindo uma nova ligação entre $\mathrm{N}$ e Ni, sem a necessidade de um $\mathrm{N}\left(\mathrm{sp}^{2}\right)$. A reação foi testada entre amidas e difenilacetilenos, utilizando diferentes condições, e pode-se confirmar que o uso de bases fortes foi eficiente. Após obter as condições otimizadas, o efeito dos substituintes no nitrogênio foi também examinado. 


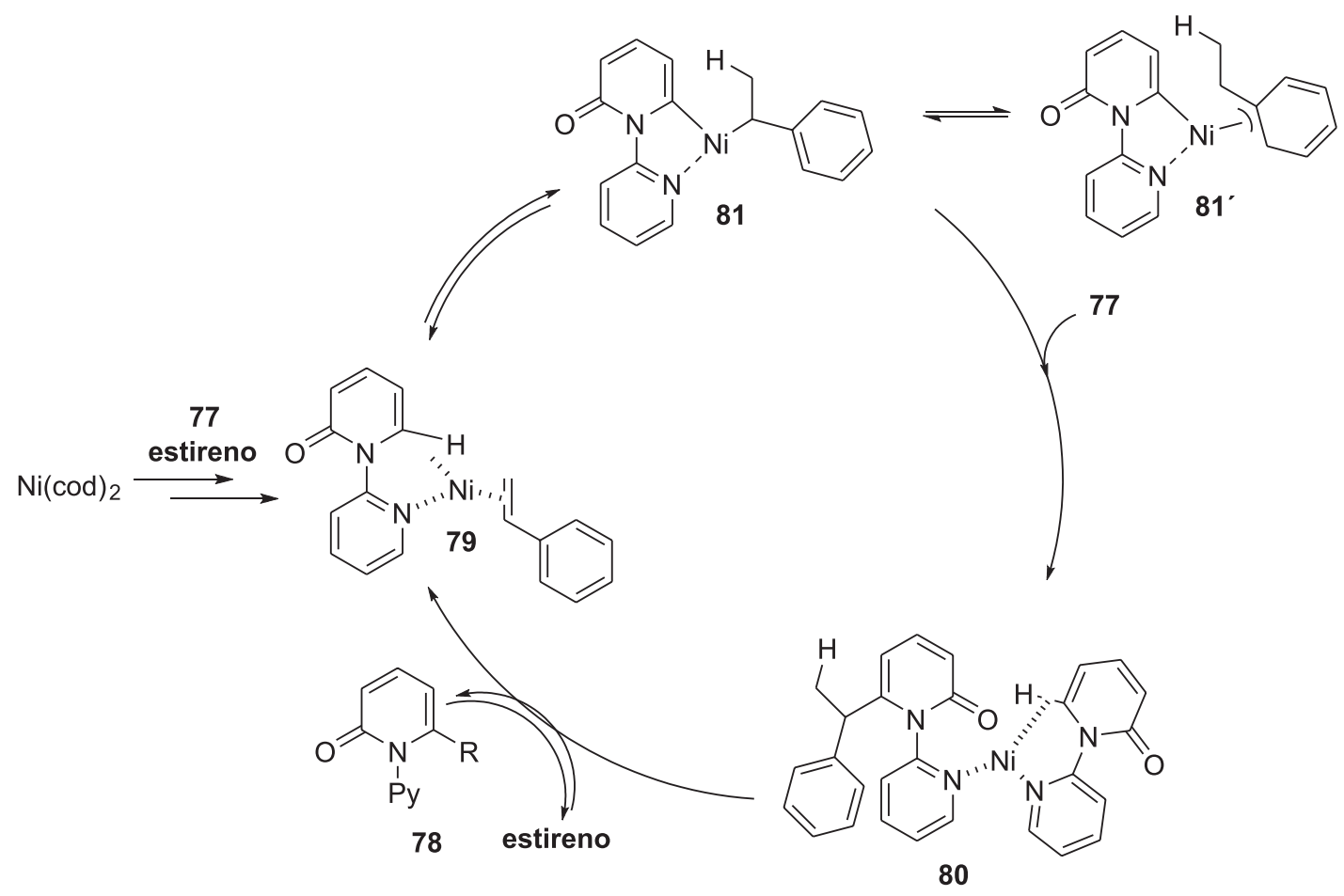

Esquema 21. Ciclo catalítico proposto para reação de alquilação de 2-piridonas com dienos e alcenos ativados

Reação catalisada por $\mathrm{Ni}(0)$

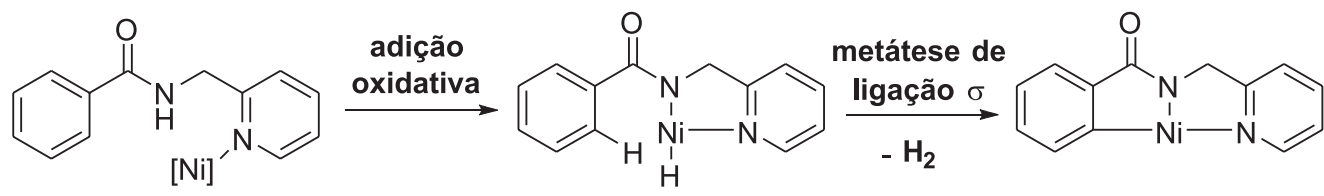

\section{Reação catalisada por $\mathrm{Ni}(\mathrm{II})$}<smiles>[X][n+]1cccc2cccc(NC(=O)c3ccccc3)c21</smiles>

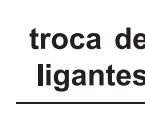<smiles>[X][C@@H]1c2ccccc2N(C(=O)c2ccccc2)[C@@H]1C</smiles>

83

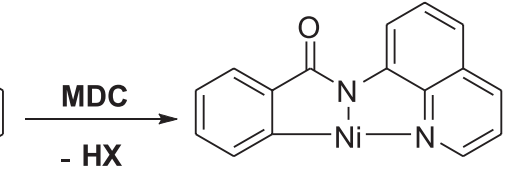

84

Esquema 22. Etapas chaves da ativação

Grupos arilas contendo grupos retiradores ou doadores de elétrons geraram as correspondentes isoquinolinas com altos rendimentos, porém o uso de grupos alquilas produziram os produtos com baixos rendimentos. Em seguida, o escopo de substratos dessa reação de anulação oxidativa foi avaliado em relação as amidas (Esquema 23). Diversos grupos funcionais nos substratos se mostraram tolerantes a metodologia, gerando produtos com rendimentos que variaram entre 32 a $91 \%$. Diferentes alcinos também foram utilizados, e rendimentos entre $<5 \%$ e $77 \%$ foram obtidos através de uma mistura de regioisômeros que variou entre 3:1 até a obtenção de apenas um isômero. ${ }^{28}$

Com intuito de determinar o mecanismo, experimentos controle foram executados, como a reação com marcação isotópica de deutério, que não foi possível observar troca de H/D no produto e na amida recuperada. Assim, conclui-se que a clivagem da ligação C-H é irreversível. O efeito cinético isotópico de 3,7 sugeriu que a etapa de clivagem da ligação C-H é a etapa determinante de velocidade.
Pode-se observar também que a função do alcino não é de apenas componente de acoplamento, ele também é um aceptor de hidrogênio. ${ }^{28}$

De acordo com os autores, o mecanismo envolve dois caminhos (Esquema 24). O complexo de Ni(II) se inicia no primeiro caminho. Um próton é abstraído da amida pelo $\mathrm{KOBu}^{\mathrm{t}}$ gerando o ânion amidato 91, que reage com $\mathrm{Ni}(\mathrm{II})$ para formar o complexo 92. A clivagem da ligação C-H orto gera o níquelciclo 93, seguido pela inserção do alcino na ligação $\mathrm{N}-\mathrm{Ni}$, que então sofre eliminação redutiva para gerar a isoquinolina e o $\mathrm{Ni}(0)$. O $\mathrm{Ni}(0)$ não pode ser oxidado a $\mathrm{Ni}(\mathrm{II})$ sob as condições reacionais empregadas. Porém, o ciclo catalítico, no qual o Ni(0) é a espécie catalítica chave, inicia-se no caminho 2. O ânion amidato 91, reage com $\mathrm{Ni}(0)$ gerando o complexo de níquel 95, o qual é suficientemente reativo para sofrer adição oxidativa, gerando espécies de hidreto de níquel 96, pois o complexo é suficientemente rico em elétrons. A inserção excessiva de alcinos nas ligações $\mathrm{H}-\mathrm{Ni}$ e C-Ni geram o complexo 98. A eliminação redutiva, seguida pela protonação de ${ }^{\mathrm{B} u O H}$ gera a isoquinolina com a regeneração de $\mathrm{Ni}(0)$ 


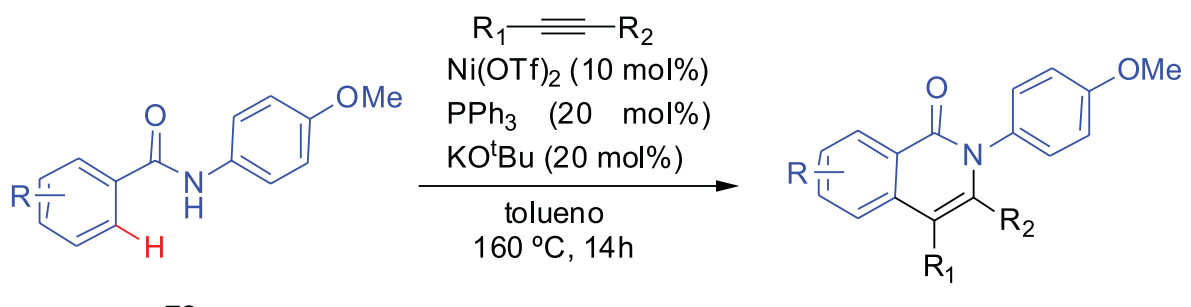

78<smiles>COc1ccc(-n2c(-c3ccccc3)c(-c3ccccc3)c3cc(C(C)(C)C)ccc3c2=O)cc1</smiles>

80 $88 \%$<smiles>COc1ccc(-n2c(-c3ccccc3)c(-c3ccccc3)c3ccc(C(F)(F)F)cc3c2=O)cc1</smiles>

81

$91 \%$
79

\section{4 exemplos \\ $5 \%-91 \%$ \\ 1:1- >20:1}<smiles>COc1ccc(-n2c(-c3ccccc3)c(Cc3ccccc3)c3ccccc3c2=O)cc1</smiles>

82

$77 \%$

$(>50: 1)$

Esquema 23. Reação entre amidas aromáticas e difenilacetilenos catalisadas por níquel

e $\mathrm{KOBu}^{\mathrm{t}}$ com concomitante formação de alcenos. Um mecanismo alternativo (Esquema 25) seria a inserção de um alcino na ligação $\mathrm{N}-\mathrm{Ni}$ em 95 gerando o complexo 99. A adição oxidativa da ligação $\mathrm{C}-\mathrm{H}$ orto gerando um niquelciclo de sete membros $\mathbf{1 0 0}$, o qual permite a inserção de um alcino, levando ao complexo 101. Esse complexo sofre eliminação redutiva e protonação pelo ${ }^{\mathrm{BuOH}}$, gerando a isoquinolina com a regeneração do $\mathrm{Ni}(0)$ e $\mathrm{KOBu}^{\mathrm{t}}$, com a concomitante formação de um alceno. ${ }^{28}$

Wei e colaboradores desenvolveram um método para a clivagem de ligações sp $^{2} \mathrm{C}-\mathrm{H}$ e C-N, catalisadas por níquel, na reação entre amidas aromáticas contendo 8- aminoquinolinas com sais de amônio benzílico. Após otimizar as condições reacionais, uma varredura do contra ânion foi investigada. Foi observado que o uso de iodeto e cloreto geravam produtos com rendimentos mais baixos, enquanto o uso de triflato e hexafluorfosfato não conduzia ao produto (Esquema 26). Em seguida, um escopo de substratos de carboxamidas foi avaliado com o uso de diferentes 8-aminoquinolinas benzamidinas. Os produtos foram obtidos com rendimentos que variaram entre 58 e $94 \%$. As reações foram mais sensíveis a fatores estéreos. O escopo de sais de amônio benzílicos também foi avaliado e tanto os substratos contendo grupos doadores de elétrons quanto os substratos contendo grupos retirados de elétrons toleraram o método. Os produtos foram obtidos rendimentos entre 81 e $99 \%$. Apenas na presença do nitro o rendimento foi moderado, com apenas $52 \%$. $^{29}$

Reações controle foram executadas a fim de investigar o mecanismo, utilizando marcação isotópica com deutério. Foi observado que uma significativa quantidade de troca H/D foi obtida, porém apenas na ligação C-H orto da amida recuperada, indicando, dessa forma, que a clivagem da ligação C-H é reversível. Um efeito isotópico cinético de 1,6 foi obtido, sugerindo que a clivagem da ligação C-H não está envolvida na etapa determinante de velocidade. Reações envolvendo captura de radicais também foram executadas e concluiu-se a presença desses no meio. Diante dos experimentos controle, o mecanismo exposto no Esquema 27 foi sugerido. A coordenação da amida com $\mathrm{Ni}$ seguida pela troca de ligantes gera o $\mathrm{Ni}(\mathrm{II})$ contido no complexo 105. A cicloniquelação desse intermediário via ativação $\mathrm{C}-\mathrm{H}$ forma o complexo de $\mathrm{Ni}$ (II) 106, que é oxidado ao complexo de $\mathrm{Ni}$ (III) 107 por um radical benzílico. A eliminação redutiva do intermediário
107 seguida pela protonação gera o produto desejado e espécies de $\mathrm{Ni}(\mathrm{I})$ com sais de amônio benzílico. O tratamento das espécies de $\mathrm{Ni}(\mathrm{I})$ com os sais de amônio benzílico produzem radicais benzil e espécies de $\mathrm{Ni}(\mathrm{II}) .^{29}$

O estado de transição da eliminação redutiva apresentado no Esquema 28, pode explicar a baixa velocidade e rendimento observados, quando, por exemplo, grupos retirados de elétrons estão presentes nos sais de amônio benzílico. ${ }^{29}$

Recentemente, Cramer e colaboradores reportaram uma classe de carbenos N-heterociclos (NHCs) quirais, com o objetivo de substituir o ligante IPr e demonstrar seu potencial na funcionalização C-H enantiosseletiva de piridonas catalisadas por níquel(0). Após otimizar os parâmetros reacionais, diversas 2-piridonas foram testadas (Esquema 29). Diversos grupos alquila e substituintes aromáticos $\mathrm{R}$ foram testados. Produtos com grupos doadores e retiradores de elétrons, assim como estericamente mais impedidos, como grupos toluil na posição orto puderam ser obtidos, com pouca influência na performance da reação. Rendimentos que variaram entre 42 e $90 \%$ e razão enantiomérica de 50:50 até 99:1 foram obtidos. Derivados de uracila também foram testados nas condições da metodologia e reagiram com a mesma eficiência, gerando produtos com excelentes rendimentos e enantiosseletividades. 4-Piridonas também foram exploradas, gerando produtos com rendimentos entre $51-91 \%$ e 94:6-99:1 r.e. ${ }^{30}$

Assim como o IPr, os carbenos quirais são estáveis e podem ser isolados. Acredita-se que complexos de níquel trissubstituídos tem a função chave de transferência de hidrogênio de ligante para ligante e consequentemente ter uma etapa enantiodeterminante. ${ }^{30}$

\section{SISTEMAS CATALÍTICOS DUPLOS: FOTOCATALISADORES E NÍQUEL}

Recentemente, a catálise fotoredox por luz visível tem emergido como um paradigma capaz de realizar diversas transformações químicas através da transferência por um único elétron (SET). A metodologia empregada, tem como vantagem a segurança, o baixo custo, a abundância e a fonte de energia renovável. ${ }^{31}$ Empregando complexos polipiridínicos com metais de transição ou corantes orgânicos como 


\section{$1^{\circ}$ caminho}

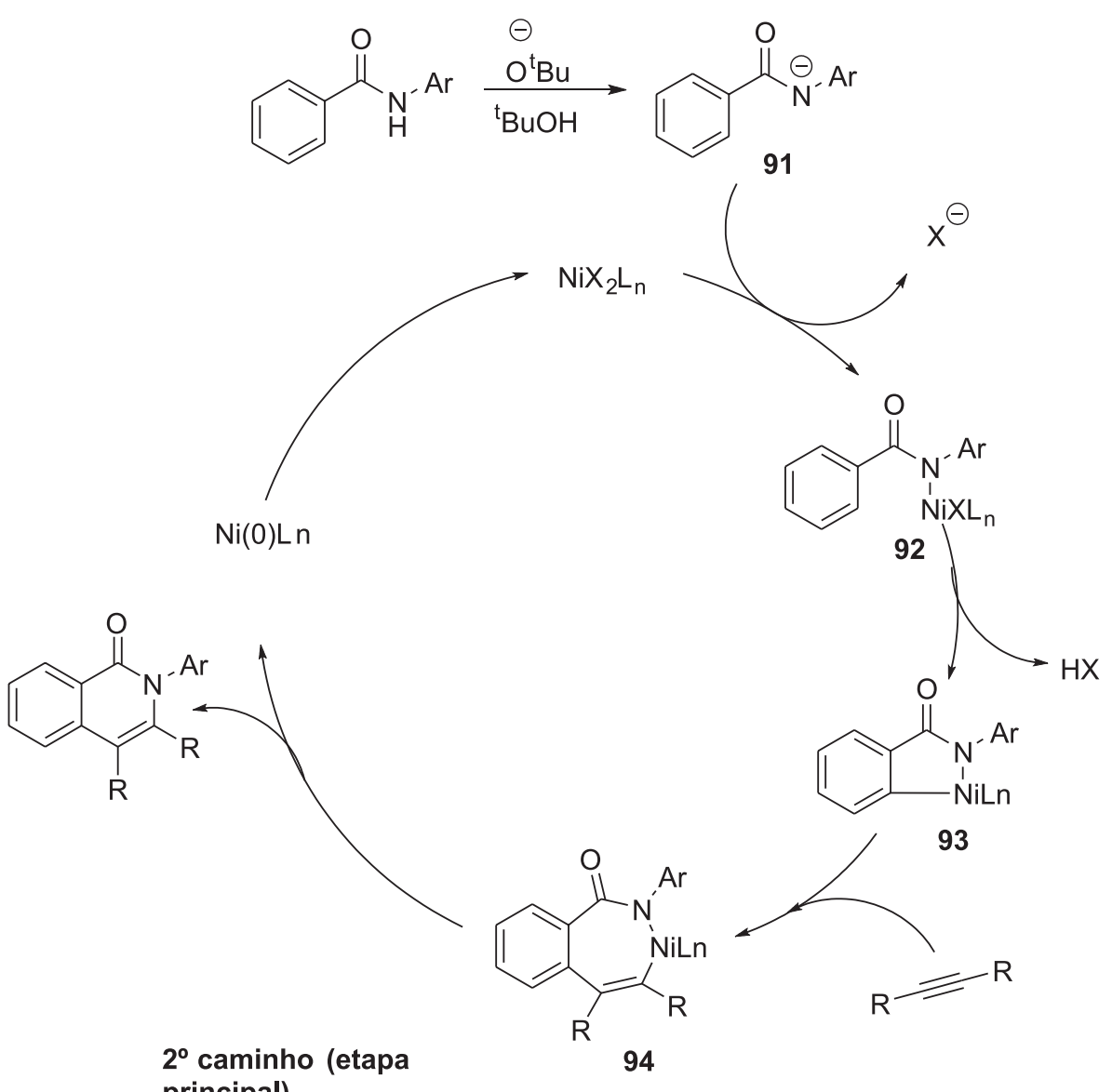

principal)

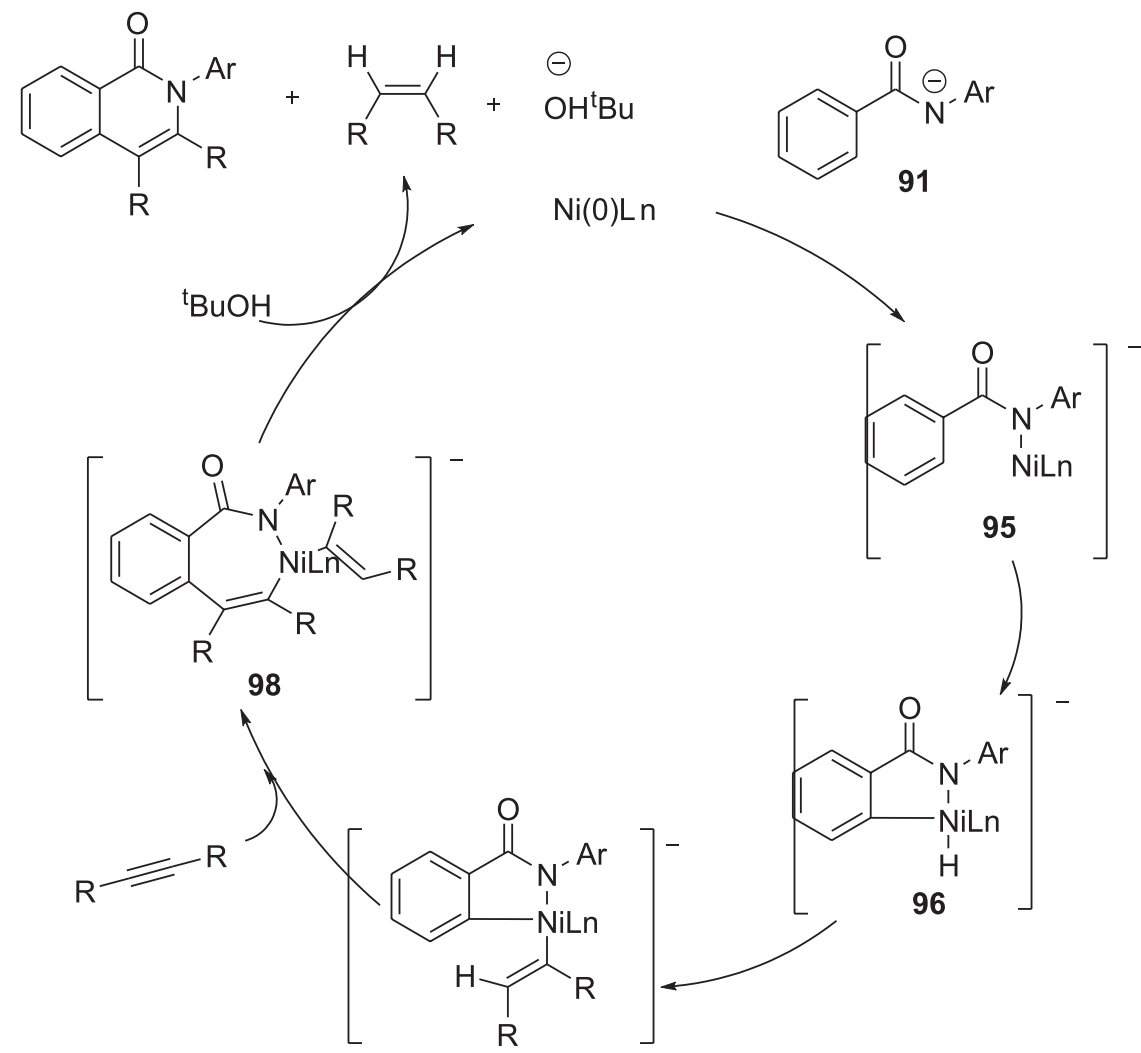

97

Esquema 24. Mecanismo proposto para reação entre amidas aromáticas e difenilacetilenos catalisadas por níquel 


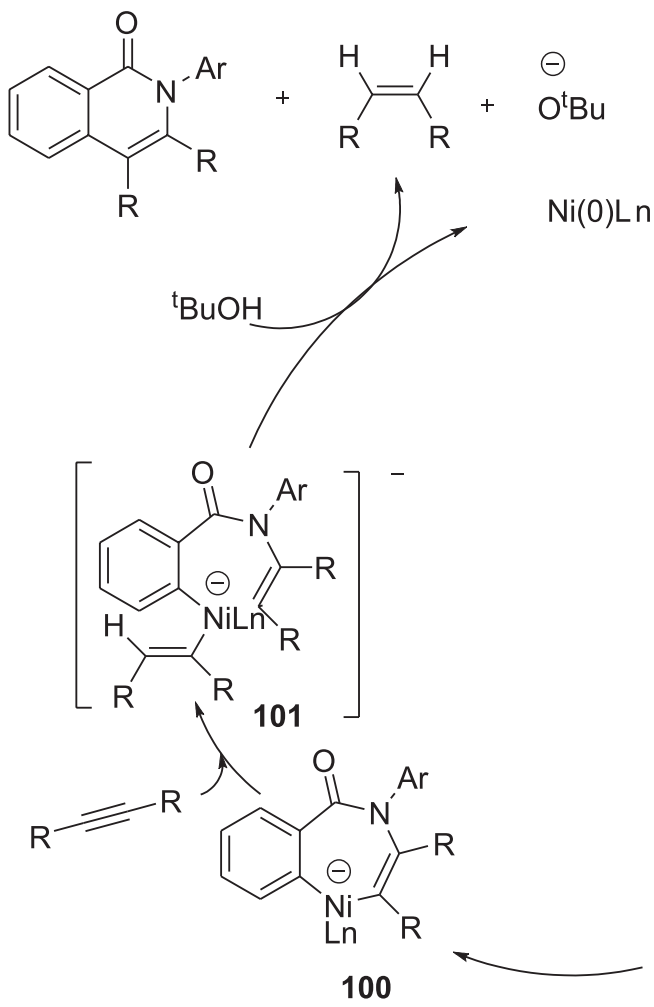

100

Esquema 25. Mecanismo alternativo de formação da isoquinolina<smiles></smiles>

102<smiles>CNCCBr</smiles>

103

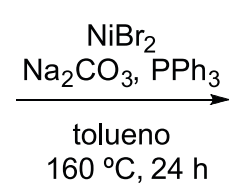

$160^{\circ} \mathrm{C}, 24 \mathrm{~h}$<smiles>O=C(Nc1cccc2cccnc12)c1cc[R1]cc1[Al]</smiles>

104 $52-99 \%$

Esquema 26. Benzilação direta de amidas aromáticas catalisadas por níquel

fotocatalisadores sob condições brandas, podem levar a um processo redox, que antes era utilizada no processo tradicional de catálise com metal de transição. Assim, a interação direta entre fotocatálise e a catálise por metais de transição provém um novo processo redox. ${ }^{32}$ Diversos grupos têm desenvolvidos trabalhos nesse âmbito, e também com a junção desses sistemas catalíticos ${ }^{32}$. Molander ${ }^{33}$, MacMillan e Doyle $^{34}$, por exemplo, em 2014, reportaram simultaneamente, duas metodologias elegantes para o acoplamento cruzado entre nucleófilos alquílicos e haletos de arila, utilizando uma catálise por níquel e fotocatalisadores. ${ }^{35}$ Após estes trabalhos, diversos grupos começaram a desenvolver metodologias com esse sistema catalítico duplo (fotocatalisadores e níquel), em diversos tipos de transformações ${ }^{36}$. Alguns trabalhos recentes foram selecionados e serão demonstrados a seguir.

Shibasaki e colaboradores reportaram a $\alpha$ acilação direta $\mathrm{C}\left(\mathrm{sp}^{3}\right)-\mathrm{H}$ de éteres através do sinergismo entre a catálise de Ir/Ni. Foi utilizado a combinação dos sistemas catalíticos compostos por $\operatorname{Ir}\left[\mathrm{dF}\left(\mathrm{CF}_{3}\right)\right.$ ppy $]_{2}(\mathrm{dtbbpy}) \mathrm{PF}_{6}\left(\mathrm{dF}\left(\mathrm{CF}_{3}\right)\right.$ ppy e complexos de níquel a temperatura ambiente, sob irradiação da luz visível (LED azul de $21 \mathrm{~W}$ ) (Esquema 30). Após otimizar as condições reacionais, um escopo com diferentes cloretos de acila e éteres foram testados. A variedade de cloretos de benzoíla e acila contendo grupos doadores e retiradores de elétrons puderam ser acoplados com éteres, gerando produtos com rendimentos que variaram entre 43 e $81 \% .^{37}$

Experimentos controle foram realizados a fim de estabelecer alguns aspectos mecanísticos. A reação de competição utilizando THD/THF- $d_{8}(1 / 1, v / v)$ como substrato, levou a uma alta fração do produto derivado de $\operatorname{THF}\left(\mathrm{k}_{\mathrm{H}} / \mathrm{k}_{\mathrm{D}}=2,4\right)$, indicando que a clivagem da ligação $\alpha-\mathrm{C}\left(\mathrm{sp}^{3}\right)$-H está envolvida na etapa determinante de velocidade. Como os éteres possuem alto potencial de oxidação (para o THF, $E=1,75 \mathrm{~V}$ vs SCE), a clivagem da ligação $\alpha$-oxi $\mathrm{C}\left(\mathrm{sp}^{3}\right)-\mathrm{H}$ através do processo de transferência por um único elétron (SET)/ desprotonação iniciado pela excitação de $\operatorname{Ir}\left[\mathrm{dF}\left(\mathrm{CF}_{3}\right) \text { ppy }\right]_{2}(\mathrm{dtbbpy}) \mathrm{PF}_{6}$ $\left(\mathrm{E}_{1 / 2}{ }^{{ }^{* I I I / I I}}=1,21 \mathrm{~V}\right.$ vs SCE em $\left.\mathrm{CH}_{3} \mathrm{CN}\right)$ foi desfavorável. Um experimento foi testado entre $\mathbf{1 2 0}$ e diversos fotosensibilizadores pela radiação da luz visível para avaliar a hipótese que radicais cloreto poderiam ser formados pela homólise $\mathrm{Ni}-\mathrm{Cl}$ do complexo de $\mathrm{Ni}$ (II) 120, através de uma transferência de energia do fotocatalisador excitado de Ir. Os resultados obtidos sugeriram que a oxidação do $\mathrm{Ni}(\mathrm{II})$ para $\mathrm{Ni}$ (III) via transferência de um único elétron não pode ser obtida pela reação. Na verdade, a irradiação UV do complexo 120 no estado excitado singleto que leva ao estado excitado tripleto através do cruzamento e da inter-relaxação entre os sistemas. Após todos as 


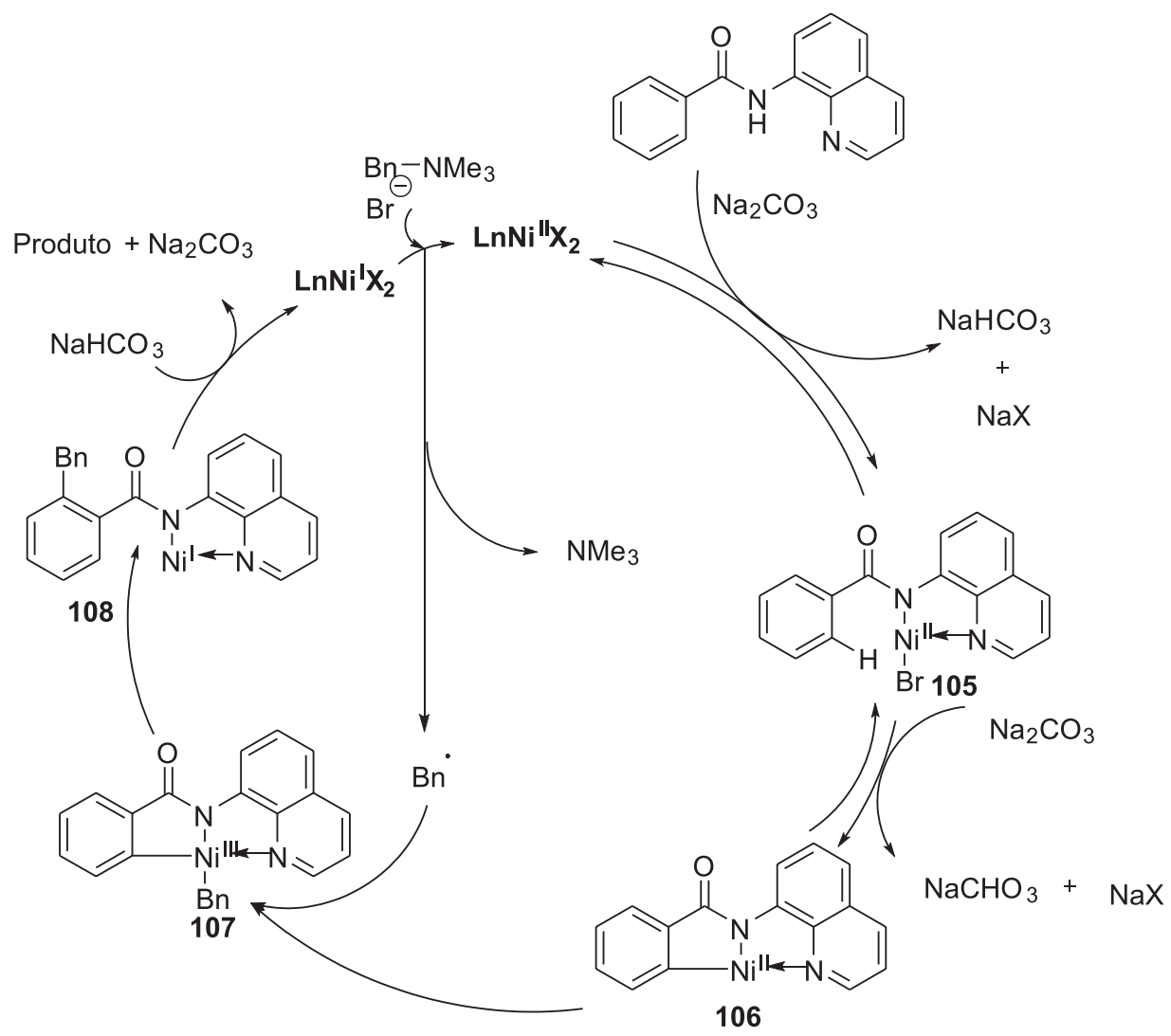

Esquema 27. Mecanismo proposto para reação de benzilação direta de amidas aromáticas catalisadas por níquel<smiles></smiles>

Esquema 28. Estado de transição para eliminação redutiva.

reações controle, um ciclo catalítico plausível foi elaborado, como está demonstrado no Esquema 31. O fotossensibilizador de Ir, com alto $\mathrm{E}_{\mathrm{T}}$, transporta energia de seu estado excitado tripleto para o complexo de $\mathrm{Ni}(\mathrm{II})$, gerado pela adição oxidativa do cloreto de acila $\mathbf{1 1 7}$, atraído pela transferência de energia tripleto-tripleto para produzir um estado de tripleto do complexo de $\mathrm{Ni}$ (II) 119. Esse intermediário sofre homólise Ni-Cl para gerar o radical cloro, o qual é responsável pela abstração de $\alpha$-hidrogênio nos éteres. A captura subsequente dos radicais $\alpha$-oxi $\mathrm{C}\left(\mathrm{sp}^{3}\right)$ formados pelo catalisador de níquel gera 121. A eliminação redutiva de $\mathbf{1 2 1}$ proporciona o correspondente produto $\alpha$-acilado 118 e regenera o complexo de $\mathrm{Ni}(0)$ para levar a subsequente regeneração do ciclo catalítico. Foi também relatado a possibilidade do uso de $\mathrm{NiCl}_{2}$, como fonte de $\mathrm{Ni}^{37}$

$\mathrm{O}$ grupo de Helal desenvolveu a primeira reação desulfinativa metalafotoredox de acoplamento $\mathrm{Csp}^{2}-\mathrm{Csp}^{3}$ entre sais de sulfinato de alquila e haletos de arila catalisada por $\mathrm{Ni} / \mathrm{Ru}$. Foi idealizado que os sais de sulfinato de alquila poderiam servir como radicais precursores nas reações metalofotoredox. Acreditou-se que o ciclo catalítico poderia ser gerado através de um radical alquila intermediário, pela oxidação do sal sulfinato, que é obtido pela oxidação de apenas um elétron (SET) do seu respectivo sal, através da excitação do estado tripleto do fotocatalisador $\left[\mathrm{PC}^{\mathrm{n}}\right]^{*}$, seguido pela liberação de $\mathrm{SO}_{2}$. A subsequente geração do radical alquila poderia interceptar o ciclo catalisado por Ni, seguindo o mecanismo proposto por Molander e Kozlowski. $^{38}$

O escopo de substratos com diferentes haletos de arila foram testados levando a produtos farmaceuticamente importantes com rendimentos que variaram entre 17 e $86 \%$ (Esquema 32). Um escopo com diferentes sais de sulfinatos também foram explorados e produtos com rendimentos que variaram entre 30 e $73 \%$ puderam ser isolados. ${ }^{38}$

Após o sucesso na avaliação de substratos, o método foi testado na síntese de um intermediário útil para a rota sintética de um fármaco (Esquema 33). O composto $\mathbf{1 2 9}$ foi utilizado para a síntese de um inibidor seletivo ATP-competitivo da caseína quinase $1 \delta$, que está associada com a regulação do ritmo circadiano. Os produtos foram obtidos com rendimentos que variaram entre 2 e $40 \%$.

Chen e colaboradores reportaram uma metodologia nova para o acoplamento cruzado de aziridinas e alquiltrifluoroborato de potássio catalisados pelo sistema duplo fotocatalisadores/níquel. O protocolo requer uma abordagem branda para a síntese de aminas $\beta$-substítuidas. Após estabelecer as condições reacionais otimizadas, um escopo de substratos de aziridinas foi avaliado (Esquema 34). O sistema de dupla catálise se mostrou eficiente e compatível para diversos grupos funcionais. Produtos com rendimentos entre moderados e bons puderam ser obtidos (entre 30 e $71 \%$ ). Diversos trifluoroboratos de alquila também foram testados e os produtos desejados puderam ser obtidos com rendimentos que variaram entre 36 e $75 \%$. Para demonstrar o potencial sintético do protocolo, uma aplicação em fluxo contínuo foi realizada e apresentou bom desempenho, com eficiência de 58\% de rendimento. Essa descoberta também implicou que o processo de fotoreação poderia ser a etapa determinante de velocidade. ${ }^{39}$

Um mecanismo plausível foi proposto como está demonstrado no Esquema 35. Primeiro, o catalisador de Ni(0) 134, formado in situ pelo pre-catalisador de $\mathrm{Ni}(\mathrm{II})$, sofre uma inserção oxidativa, na ligação C-N mais volumosa da aziridina 131, proporcionando o 
<smiles>[R]C=C([R])CCn1c([2H])cccc1=O</smiles>

109

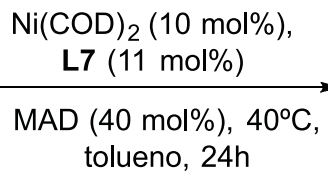

$\operatorname{MAD}(40 \mathrm{~mol} \%), 40^{\circ} \mathrm{C}$, tolueno, $24 \mathrm{~h}$<smiles>[R]C1CCn2c(cccc2=O)C1[R]</smiles>

110

20 exemplos

$42-90 \%$

50:50-99:1
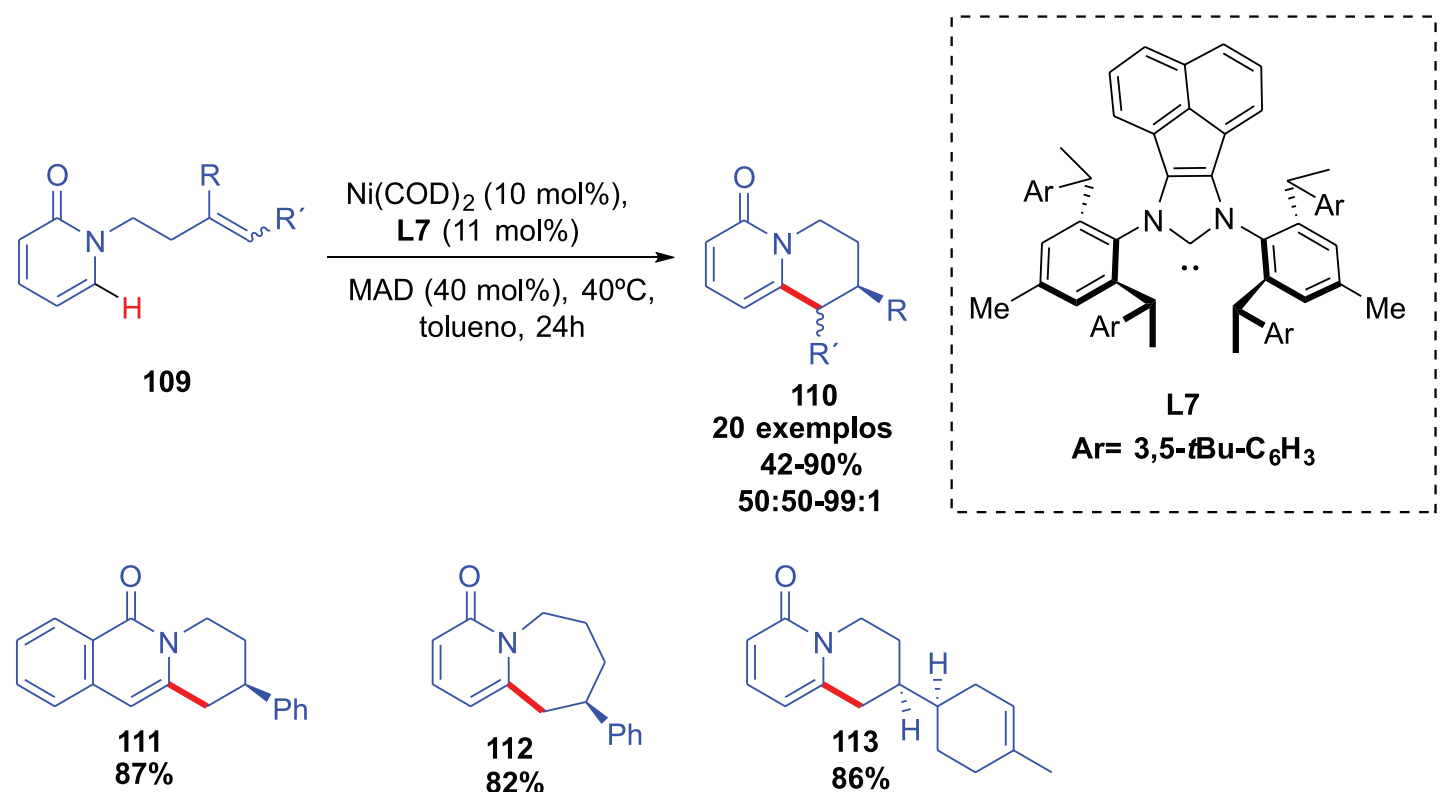<smiles>O=c1cccc2n1CCC[C@H](c1ccccc1)C2</smiles>
95:5 r.e.

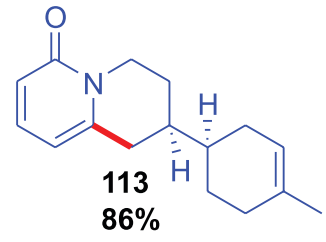

$98.5: 1,5$ r.e.<smiles>[R]C(=C)CCn1ccc(=O)[X]c1=O</smiles>

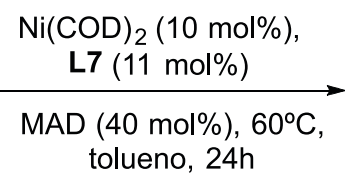<smiles>[R]C1CCn2c(cc(=O)[X]c2=O)C1</smiles>

6 exemplos

$51-91 \%$,

94:6-99:1 r.e

Esquema 29. Funcionalização C-H enantiosseletiva de piridonas catalisadas por níquel.<smiles>[R20]C([R2])[CH-]C(=O)Cl</smiles><smiles>[R2]C(=O)C([R])[R2]</smiles>

azaniquelciclobutano 135. A regiosseletividade pode ser atribuída as diferentes propriedades eletrônicas na deficiência de elétrons do ligante. Enquanto isso, 109 é convertido ao radical benzílico 136, para gerar o estado fotoexcitado do Ir(III)*, através da transferência de um único elétron no processo de oxidação. Assim, as espécies de $\mathrm{Ni}$ (II) são rapidamente capturadas pelo radical benzílico 136, gerando o intermediário alquilníquel(III) 137. A eliminação redutiva do intermediário 137 gera as espécies de $\mathrm{Ni}(\mathrm{I}) \mathbf{1 3 8}$, que sofrem outra redução pela transferência de um único elétron através da forma reduzida do fotocatalisador de $\operatorname{Ir}($ II). Esse processo fornece o produto 133 pela protonação do intermediário $\mathbf{1 3 9}$, com liberação do fotocatalisador de $\operatorname{Ir}(\mathrm{III})$, fechando assim, os dois ciclos catalíticos. ${ }^{39}$

O grupo de Monolikakes reportou a síntese de sulfonas por sulfinatos de sódio ou lítio e iodetos de arilas catalisadas pelo sistema duplo de fotocatalisador e níquel. Diversos sulfinatos de sódio foram testados com diferentes iodetos de arila e heteroarila (Esquema 36). Produtos contendo grupos retirados de elétrons e doadores de elétrons puderam ser obtidos, assim como em diferentes posições do anel aromático, com rendimentos que variaram entre 14 e $89 \%$. A metodologia foi ainda testada na última etapa da síntese de drogas, como fenazona 145 e sildenafil 146, levando aos produtos com 38 e $33 \%$ de rendimento, respectivamente (Figura 3). Para expandir o método, reações com sulfinatos de lítio foram utilizados e geraram os produtos correspondentes com bons rendimentos. ${ }^{40}$

Experimentos controle levaram a propor o ciclo catalítico demonstrado no Esquema 37. A irradiação do fotocatalisador de $\mathrm{Ru}^{\mathrm{II}}$ 


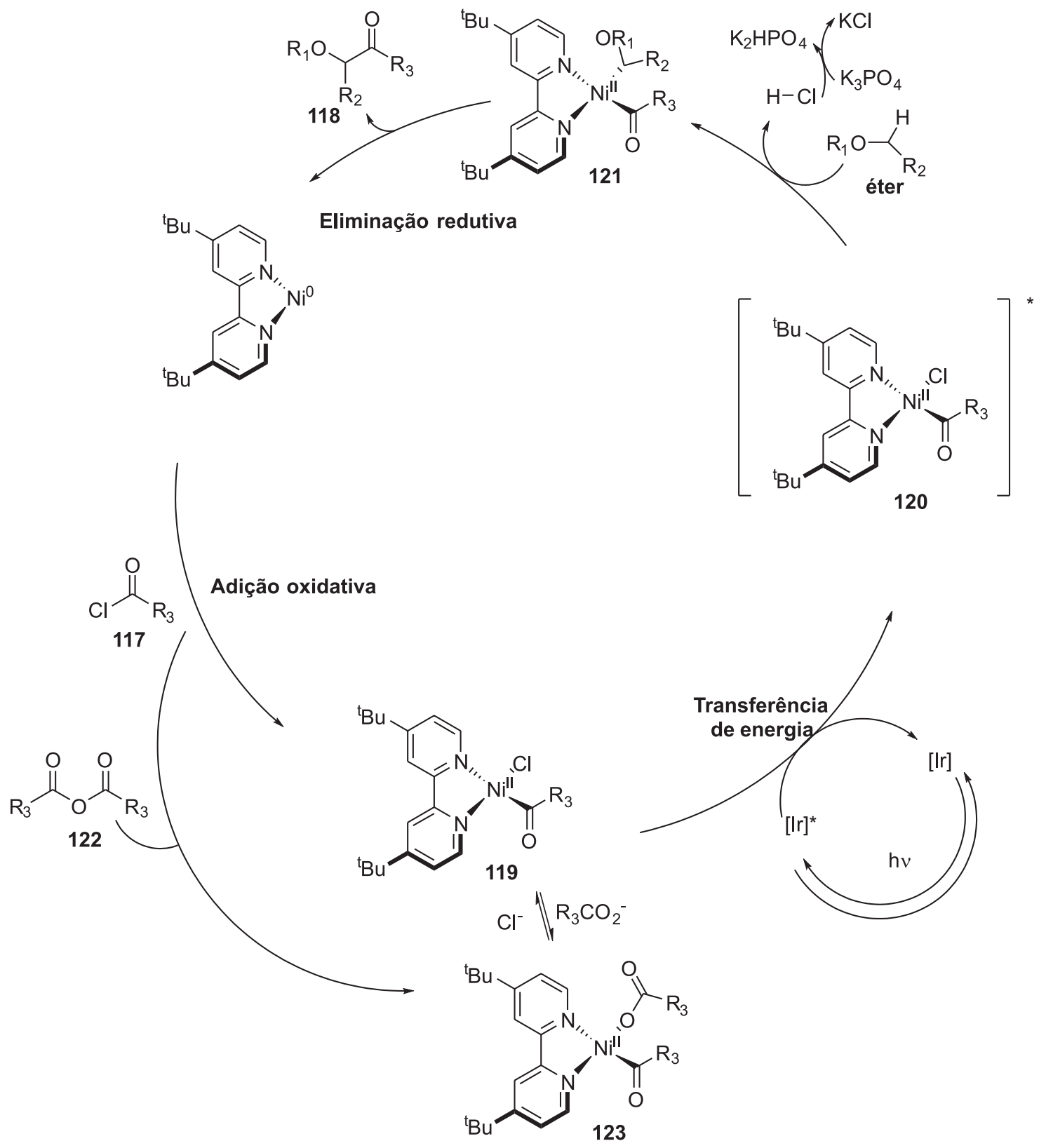

Esquema 31. Ciclo catalítico proposto para reação de $\alpha$-acilação fotocatalítica de éteres
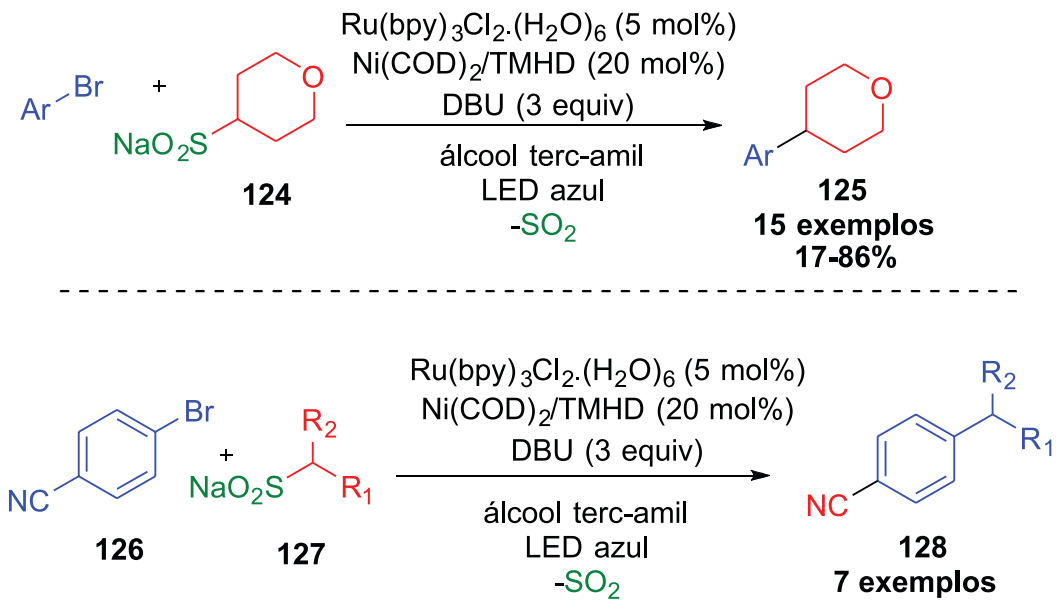

$30-73 \%$

Esquema 32. Acoplamente cruzado entre haletos de arila e sulfinatos de alquila catalisadas por Ni/Ru 


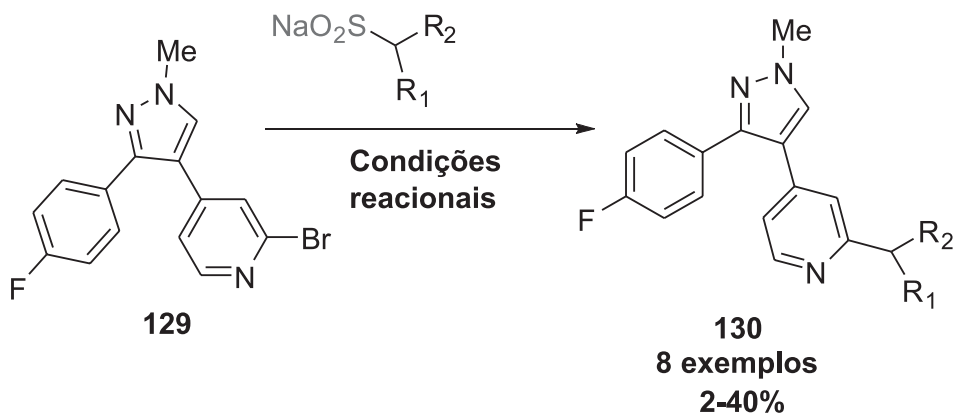

Esquema 33. Preparação do inibidor ATP-competitivo da caseína quinase $1 \delta$
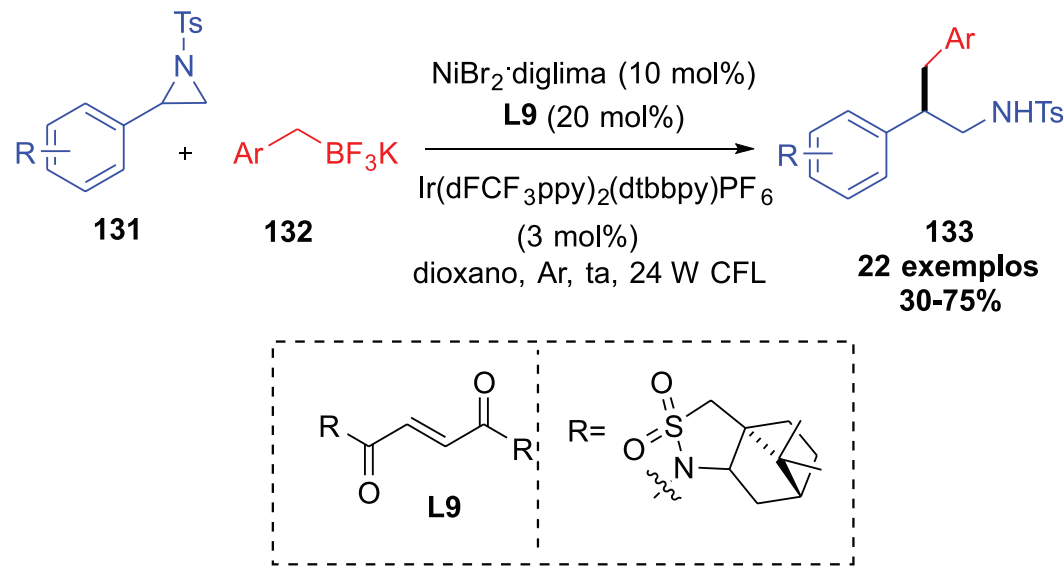

Esquema 34. Reações de acoplamento cruzado de aziridinas e benziltrifluorboratos de potássio

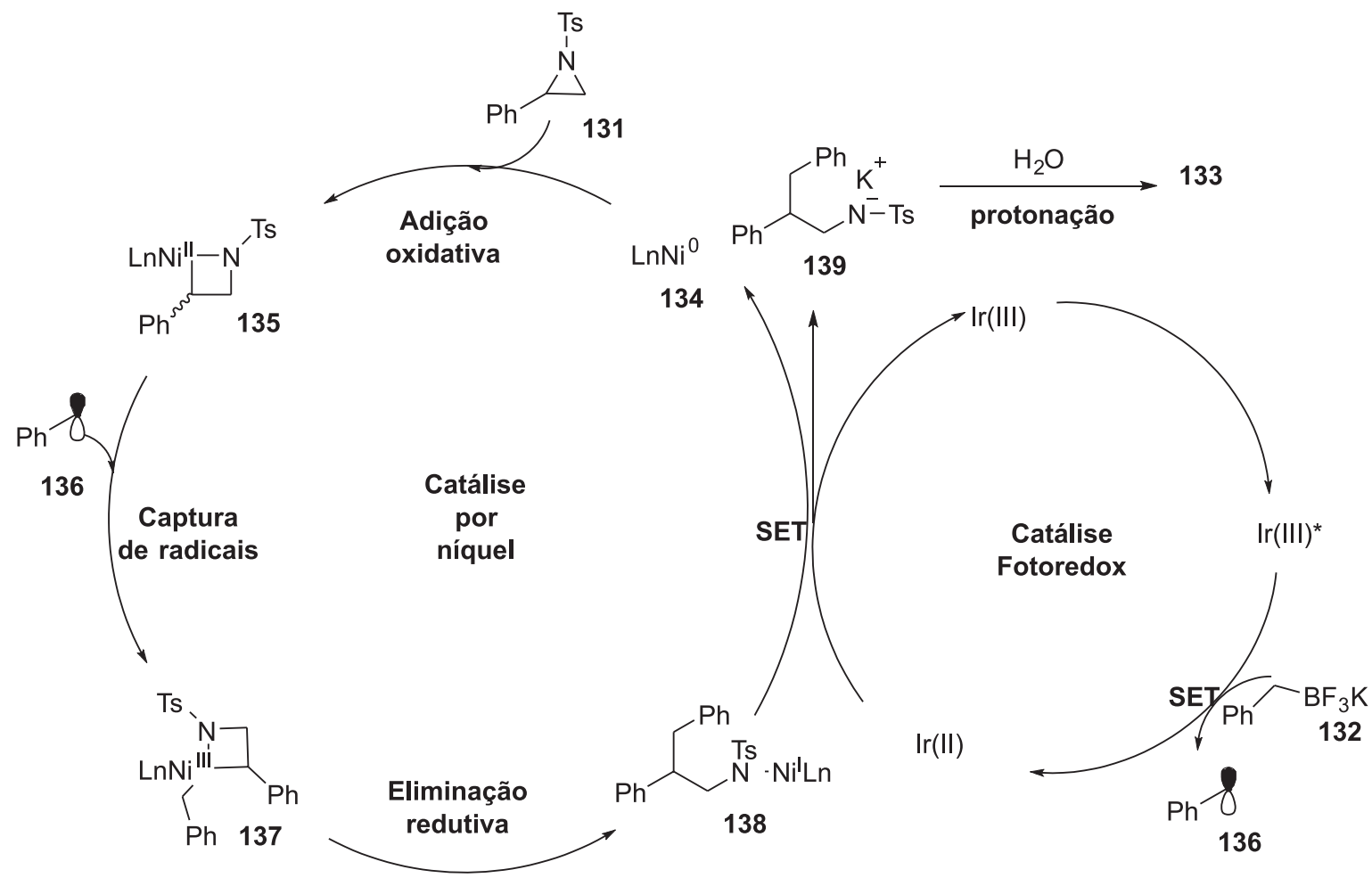

Esquema 35. Ciclo catalítico proposto para a reação de acoplamento cruzado de aziridinas e benziltrifluorboratos de potássio

gera o estado excitado de $* \mathrm{Ru}^{\mathrm{II}}$. A oxidação da transferência de um único elétron do sulfinato 147 conduz ao radical sulfonil 148 e o complexo de $\mathrm{Ru}^{\mathrm{I}}$. A adição do radical sulfonil 148 para o catalisador de $\mathrm{Ni}$ fornece o intermediário de $\mathrm{Ni}^{\mathrm{I}} \mathbf{1 4 9}$, que pode sofrer adição oxidativa ao iodeto de arila. $\mathrm{O}$ complexo de $\mathrm{Ni}{ }^{\mathrm{III}} \mathbf{1 5 0}$ sofre eliminação redutiva, gerando o produto sulfona 140 e espécies de $\mathrm{Ni}^{\mathrm{I}}-\mathrm{I}$ 151. A redução da transferência de um único elétron de $\mathbf{1 5 1}$ pelo $\mathrm{Ru}^{\mathrm{I}}$ produz o catalisador de $\mathrm{Ni}^{0}$ com o complexo de $\mathrm{Ru}^{\mathrm{II}}$ no estado fundamental, fechando o ciclo fotocatalisadores e o acoplamento cruzado. A função da amina não foi totalmente esclarecida, sugere-se uma possível mediação na 


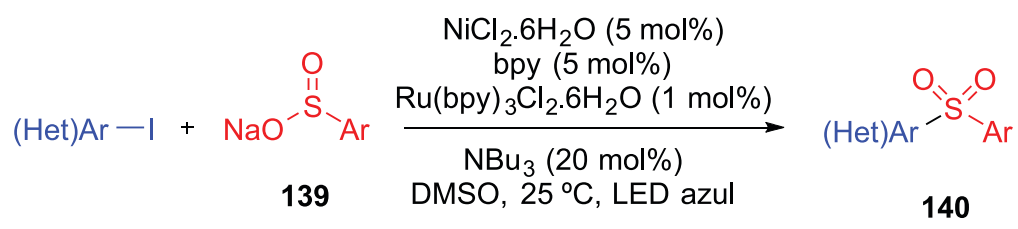

29 exemplos

$14-89 \%$<smiles>O=S(=O)(c1ccccc1)c1ccccc1O</smiles>

141

$89 \%$<smiles>O=S(=O)(c1ccccc1)c1cccnc1</smiles>

142

$84 \%$<smiles>O=S(=O)(P)c1cccs1</smiles>

143

$65 \%$<smiles>COc1ccc(S(C)(=O)=O)cc1</smiles>

144

$63 \%$

Esquema 36. Reação de acoplamento cruzado de sais de ácido sulfinico com iodetos de arila catalisadas por níquel e fotocatalisador

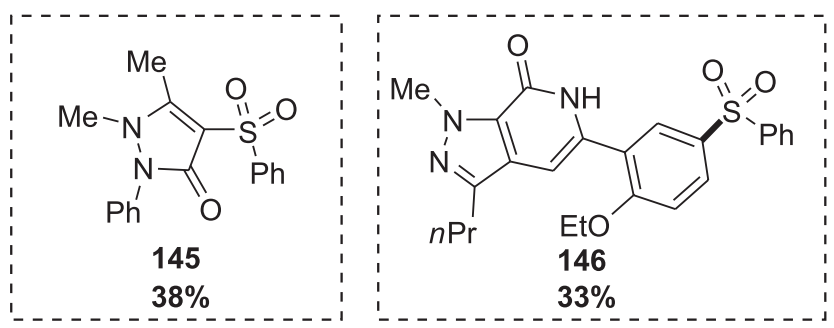

Figura 3. Aplicação sintética em compostos biologicamente ativos transferência de elétron entre os dois ciclos, evitando uma eventual degradação do sulfinato. ${ }^{40}$

Uma metodologia de hidroxilação de haletos de arila com água catalisada por um sistema duplo fotocatalisadores/níquel foi desenvolvido pelo grupo de Xue (Esquema 38). Apenas produtos monosubstituídos foram observados, demonstrando assim, um alto grau de quimiosseletividade para essa reação. Diversos produtos importantes, como intermediários de compostos bioativos puderam ser obtidos com rendimentos entre 40 e $96 \%$ (Esquema 39). O escopo foi ainda

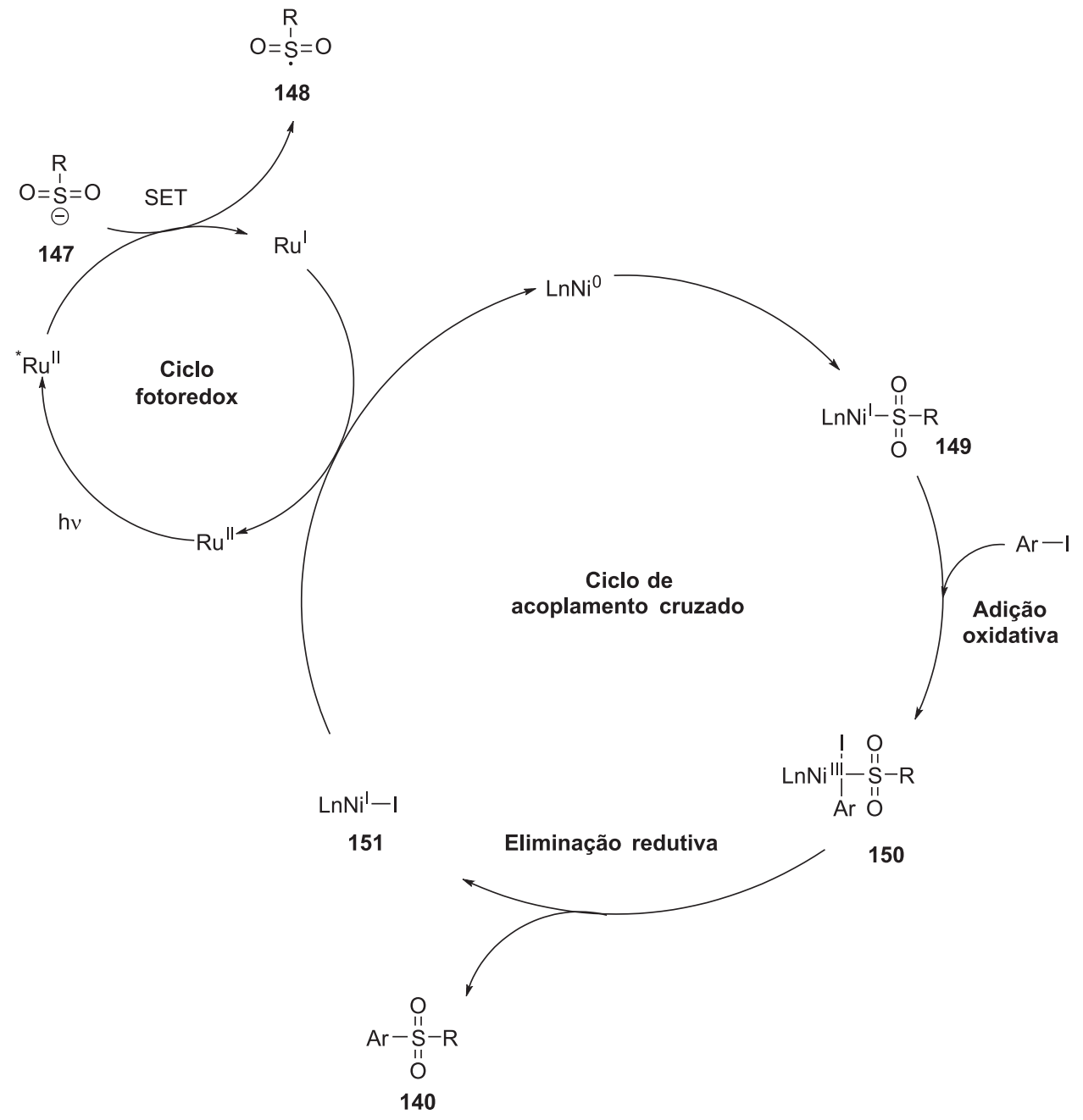

Esquema 37. Mecanismo proposto para reação de acoplamento cruzado entre sais de ácido sulfinico com iodetos de arila catalisadas por níquel e fotocatalisadores 


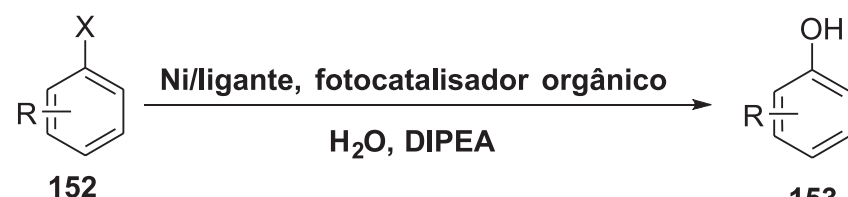

152
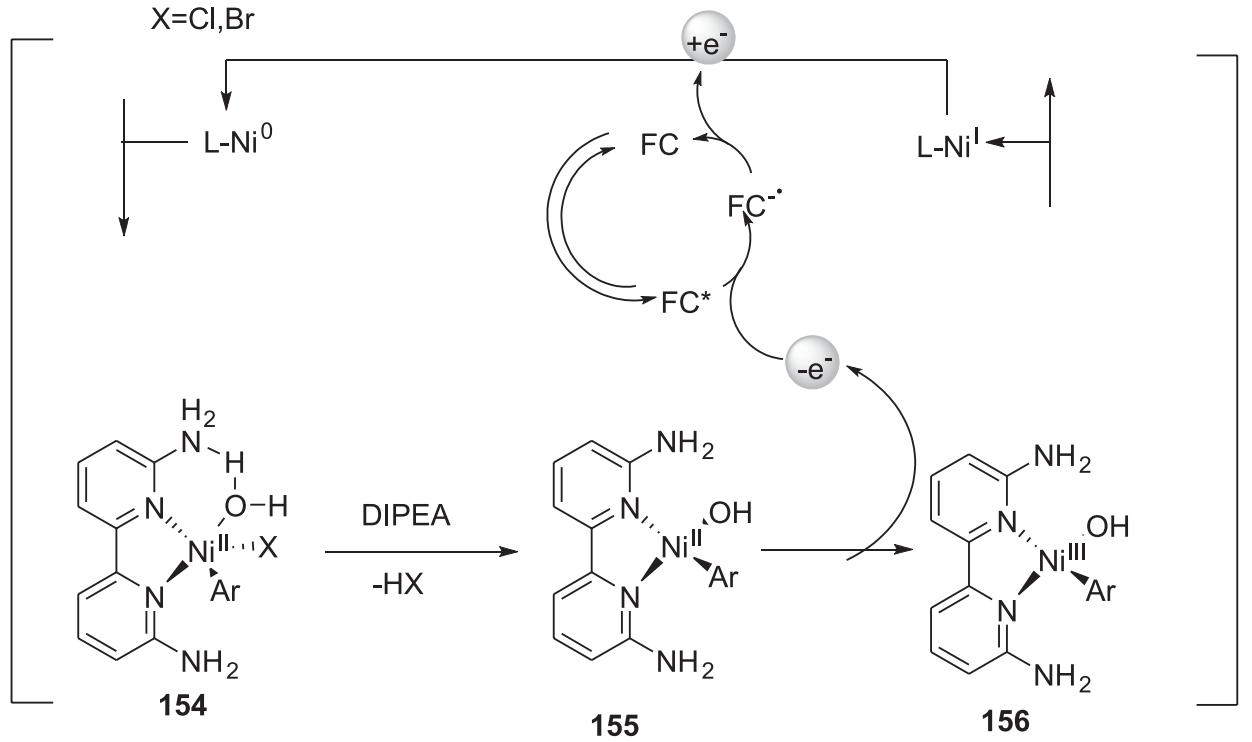

Esquema 38. Síntese de fenóis por haletos de arila

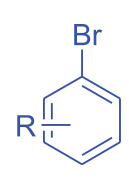

152

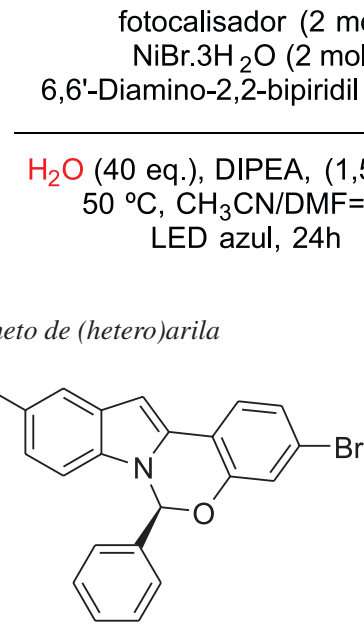

157

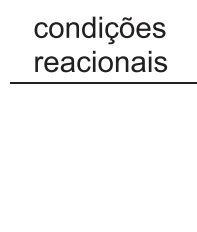

S, $97 \%$ ee

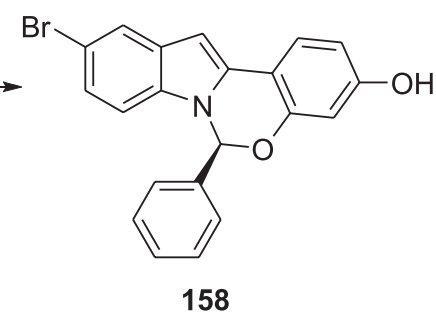

$71 \%, \mathrm{~S}, 95 \%$ ee

Esquema 40. Síntese de um intermediário do Elbasvir

expandido para substratos de menor custo, porém mais desafiadores, como os cloretos de arila. Devido à forte ligação $\mathrm{C}-\mathrm{Cl}$, não era esperado que a reação ocorresse sob as mesmas condições, porém ao aumentarem a temperatura, a reação ocorreu e gerou produtos com rendimentos entre 45 e $91 \% .^{41}$

Com intuito de demonstrar a utilidade do método, um intermediário chave do Elbasvir, um fármaco utilizado para o tratamento contra Hepatite C, foi sintetizado com um rendimento de $71 \%$, com uma pequena perda da enantiosseletividade (Esquema 40). Outra molécula mais complexa também foi testada e gerou o produto com $62 \%$ de rendimento. A metodologia foi realizada em escala maior (10 mmol), gerando o produto com $92 \%$. Para analisar se o $\mathrm{OH}$ dos produtos fenólicos vem originalmente da água, reações foram carreadas com $\mathrm{H}_{2} \mathrm{O}^{18}$. Os produtos foram obtidos com o $\mathrm{O}^{18}$ demarcados isotopicamente, demonstrando assim que o $\mathrm{OH}$ realmente é oriundo da água. ${ }^{41}$

\section{CONCLUSÕES}

Em resumo, a catálise por níquel vem se expandindo muito nos últimos anos, porém, ainda há muitos desafios que precisam ser superados. Devida a sua alta reatividade, muitas vezes, os sistemas catalíticos requerem um esforço maior no desenvolvimento, ainda que o seu potencial sintético seja indiscutível.

Destaca-se entre as maiores vantagens da catálise por complexos de níquel, entre outros, o baixo custo, a catálise com alta performance, as transformações envolvendo substratos inativos, o acesso fácil a reações em cascata, a reações de acoplamento, de ciclização e de 
fotocatálise, além de sua enorme facilidade na ativação de moléculas insaturadas, possibilitando uma variedade de transformações incomuns envolvendo ligações múltiplas.

Muitos complexos de níquel estão associados a alta toxicidade, porém foi possível demonstrar, neste trabalho, que esses complexos catalisam reações altamente relevantes, tais como reações de ativação da ligação $\mathrm{C}-\mathrm{H}^{42}$, carboxilação, carbonilação e reações de catálise dupla entre níquel e fotocatalisadores. A maioria desses processos exploram os estados de oxidação $\mathrm{Ni}(\mathrm{I}) / \mathrm{Ni}(\mathrm{III})$, que são raros quando comparamos ao Pd. Outros processos envolvendo Ni vêm sendo desenvolvidos, tais como acoplamento descarboxilativo ${ }^{43}$ e acoplamento cruzado assimétrico envolvendo eletrófilos alquila ${ }^{44,45}$.

Ainda há muito para ser desenvolvido na catálise por níquel, principalmente devido aos seus diferentes estados de oxidação, facilmente acessados. Finalmente, foi possível demonstrar um pouco da sua importância em reações orgânicas, além da sua aplicabilidade recente em síntese orgânica.

\section{AGRADECIMENTOS}

Os autores agradecem à CAPES, CNPq, FAPEMIG e a UFJF pelo suporte financeiro.

\section{REFERÊNCIAS}

1. Tasker, S. Z.; Standley, E. A.; Jamison, T.; Nature 2014, 509, 299.

2. Ananikov, V. P.; ACS Catal. 2015, 5, 1964. Li, B.-J.; Yu, D.-G.; Sun, C.-L.; Shi, Z.-J.; Chem. Eur. J. 2011, 17, 1728.; Rosen, B.; Chem. Rev. 2011, 111, 1346.; Mesganaw, T.; Garg, N. K.; Org. Process Res. Dev. 2013, 17, 29.

3. Li, B.-J.; Yu, D.-G.; Sun, C.-L.; Shi, Z.-J.; Chem. Eur. J. 2011, 17, 1728.; Rosen, B.; Chem. Rev. 2011, 111, 1346.; Mesganaw, T.; Garg, N. K.; Org. Process Res. Dev. 2013, 17, 29.

4. Garcia, J. J.; Brunkan, N. M.; Jones, W. D.; J. Am. Chem. Soc. 2002, 124, 9547.

5. Tsou, T. T.; Kochi, J. K.; J. Am. Chem. Soc. 1979, 101, 6319.

6. Moeda Americana cotada no dia 01/06/1018. 1,0 dóllar americano correspondendo a 3,756 reais.

7. Cordero, B.; Gómez, V.; Platero-Prats, A. E.; Revés, M.; Echeverría, J.; Cremades, E.; Barragan, F.; Alvarez, S.; Dalton Trans. 2008, 0, 2832.

8. Hodgeman CD. - Handbook of Chemistry and Physics, ed. 33. Chemical Rubber Publ Comp, 1951.

9. Guo, J.; Lin, L.; Liu, Y.; Li, X.; Liu, X.; Feng, X.; Org. Lett. 2016, 18, 5540-5543; Sheng, J.; Ni, H. Q.; Liu, G.; Li, Y.; Wang, X. S.; Org. Lett. 2017, 19, 4480-4483; Guangying, T.; Zhang, L.; Liao, X.; Shi, Y.; Wu, Y.; Yang, Y.; You, J.; Org. Lett. 2017, 19, 4830-4833; J. Org. Chem. 2017, 82, 6426-6433; Perkins, R. J.; Pedro, D. J.; Hansen, E. C.; Org. Lett. 2017, 19, 3755-3758; Suzuki N.; Hofstra J. L.; Poremba K. E.; Reisman S. E.; Org. Lett. 2017, 19, 2150-2153.; Li, C.; Kawamata, Y.; Nakamura, H.; Vantourout, J. C.; Liu, Z.; Hou, Q.; Bao D.; Starr J. T.; Chen, J.; Yan, M.; Baran, P. S.; Angew. Chem. Int. Ed. 2017, 56(42), 13088.

10. Andersen, T. L.; Nordeman, P.; Christoffersen, H. F.; Audrain, H.; Antoni, G.; Skrydstrup T.; Angew. Chem. Int. Ed. 2017, 56, 4549.

11. Hoshimoto, Y.; Ashida, K.; Sasaoka, Y.; Kumar, R.; Kamikawa, K.; Verdaguer,X.; Riera, A.; Ohashi, M.; Ogoshi, S.; Angew. Chem. Int. Ed. 2017, 56, 8206; Angew. Chem. 2017, 129, 8318.

12. Dolhem, E.; Oçafrain, M.; Nédélec, J. Y.; Troupel, M.; Tetrahedron 1997, 53, 17089

13. Andersen, T. L.; Donslund, A. S.; Neumann, K. T.; Skrydstrup, T.; Angew. Chem. Int. Ed. 2018, 57, 800.

14. Yu, D.; Teong, S. P.; Zhang, Y.; Coordination Chemistry Reviews, 2015, 293-294, 279.
15. Martin R.; Tortajada A.; Juliá-Hernández F.; Borjesson M.; Moragas T.; Angew. Chem. Int. Ed. 2018, DOI: 10.1002/anie.201803186.

16. Nogi, K.; Fujihara, T.; Terao, J.; Tsuji, Y.; J. Org. Chem., 2015, 80, 11618.

17. Richmond, E.; Moran, J.; Synthesis 2018, 50, 499.

18. Moragas, T.; Martin, R.; Synthesis 2016, 48, 2816.

19. van Gemmeren, M.; Börjesson, M.; Tortajada, A,; Sun, S. Z.; Okura, K.; Martin, R.; Angew. Chem. Int. Ed. 2017, 56, 6558.

20. Tortajada, A.; Ninokata, R.; Martin, R.; J. Am. Chem. Soc. 2018, 140, 2050.

21. Kleiman, J. P; Dubeck, M.; J. Am. Chem. Soc. 1963, 85, 154.

22. Okumura, S.; Tang, S.; Saito, T.; Semba, K.; Sakaki S.; Nakao Y.; J. Am. Chem. Soc. 2016, 138, 14699.

23. Okumura, S.; Nakao, Y.; Org. Lett. 2017, 19, 584.

24. Steinberg, D. F.; Turk, M. C.; Kalyani, D.; Tetrahedron 2017, 73, 2196.

25. Miura, W.; Hirano, K.; Miura, M.; J. Org. Chem. 2017, 82, 5337.

26. Aihara, Y.; Chatani, N.; J. Am. Chem. Soc. 2013, 135, 5308; Aihara, Y.; Chatani, N.; J. Am. Chem. Soc. 2014, 136, 898; Aihara, Y.; Tobisu, M.; Fukumoto, Y.; Chatani, N.; J. Am. Chem. Soc. 2014, 136, 15509; Yokota, A.; Aihara Y.; Chatani, N.; J. Org. Chem. 2014, 79, 11922; Iyanaga, M.; Aihara, Y.; Chatani, N.; J. Org. Chem. 2014, 79, 11933; Aihara, Y.; Wulbern J.; Chatani, N.; Bull. Chem. Soc. Jpn. 2015, 88, 438; Yokota, A.; Chatani, N.; Chem. Lett. 2015, 44, 902; Kubo, T.; Aihara, Y.; Chatani, N.; Chem. Lett. 2015, 44, 1365; Uemura, T. M.; Yamaguchi; Chatani, N.; Angew. Chem. Int. Ed., 2016, 55, 3162; Kubo, T.; Chatani, N.; Org. Lett. 2016, 18, 1698; Aihara, Y.; Chatani, N.; ACS Catal. 2016, $6,4323$.

27. Misal Castro, L. C.; Chatani, N.; Chem. Lett. 2015, 44, 410; Chatani, N.; Top. Organomet. Chem. 2016, 56, 19.

28. Obata, A.; Ano, Y.; Chatani, N.; Chem. Sci. 2017, 8, 6650.

29. Li, J.; Zheng, Z.; Xiao, T.; Xu, P-F.; Wei, H.; Asian J. Org. Chem. 2018, 7, 133.

30. Diesel, J.; Finogenova, A. M.; Cramer, N.; J. Am. Chem. Soc. 2018, doi: 10.1021/jacs.8b01181.

31. De Almeida, A. M.; De Almeida, M. V.; Amarante, G. W.; Quím. Nova 2015, 38, 1080.

32. Hopkinson, M. N.; Sahoo, B.; Li J. L.; Glorius, F.; Chem. Eur. J. 2014, 20,3874 .

33. Tellis, J. C.; Primer, D. N.; Molander, G. A.; Science, 2014, 345, 433.

34. Zuo, Z.; Ahneman, D. T.; Chu, L.; Terrett, J. A.; Doyle, A. G.; MacMillan, D. W. C.; Science 2014, 345, 437.

35. Gui, Y-Y.; Sun, L.; Lu, Z-P.; Yu, D-G.; Org. Chem. Front. 2016, 3, 522.

36. DeLano, T. J.; Bandarage, U. K.; Palaychuk, N.; Green, J.; Boyd, M. J.; J. Org. Chem. 2016, 81, 12525.; Amani, J.; Molander, G. A.; Org. Lett. 2017, 19, 3612.; Alam, R.; Molander, G. A.; J. Org. Chem. 2017, 82, 13728.; Matsui, J. K.; Molander, G. A.; Org Lett. 2017, 19, 436.; Liu J.; Ding, W.; Zhou, Q. Q.; Liu, D.; Lu, L. Q.; Xiao, W. J.; Org Lett. 2018, 20, 461.; Amani J.; Molander G. A.; J. Org. Chem. 2017, 82, 1856.

37. Sun, Z.; Kumagai, N.; Shibasaki, M.; Org. Lett. 2017, 19, 3727.

38. Knauber, T.; Chandrasekaran, R.; Tucker, J. W.; Chen, J. M.; Reese, M.; Rankic, D. A.; Sach, N.; Helal, C.; Org. Lett. 2017, 19, 6566.

39. Yu, X-Y.; Zhou, Q-Q.; Wang, P-Z.; Liao, C-M.; Chen, J-R.; Xiao, W-J.; Org. Lett. 2018, 20, 421.

40. Liu, N-W.; Hofman, K.; Herbert, A.; Manolikakes, G.; Org. Lett. 2018, 20,760.

41. Yang, L.; Huang, Z.; Li, G.; Zhang, W.; Cao, R.; Wang, R.; Wang, C.; Xiao, J.; Xue, D.; Angew. Chem. Int. Ed. 2018, 57, 1968.

42. De Azambuja, F.; Correia, C. R. D.; Quím. Nova 2011, 34, 1779.

43. Sandfort, F.; O’Neill, M. J.; Cornella, J.; Wimmer, L.; Baran, P. S.; Angew. Chem. Int. Ed. 2017, 56, 3319.

44. Mu, X.; Shibata, Y.; Makida, Y.; Fu, G. C. Angew. Chem. Int. Ed. 2017, $56,5821$.

45. Lucas, E. L.; Jarvo, E. R.; Nat. Rev. Chem. 2017, 1, 0065. 